\title{
PRODUÇÃO DE CONHECIMENTO E TRADIÇÕES DE PESQUISA \\ NA FACULDADE DE FILOSOFIA, CIÊNCIAS E LETRAS - USP (1934-1968)
}

MÁRCIA REGINA BARROS DA SILVA

Universidade de São Paulo (USP), São Paulo, São Paulo, Brasil

Doutora, professora do Departamento de História da Faculdade de Filosofia, Letras e Ciências Humanas da Universidade de São Paulo - FFLCH-USP, área de história da ciência. Email: marciabarrossilva@usp.br

MARIA AMÉLIA MASCARENHAS DANTES

Universidade de São Paulo (USP), São Paulo, São Paulo, Brasil

Doutora, professora Sênior do Departamento de História da FFLCH - USP, área de história da ciência. Email: mamdantes@usp.br

RECEBIDO

04/09/2015

DOI

http://dx.doi.org/10.11606/issn.1980-4466.v0i20p159-194 


\section{PRODUÇÃO DE CONHECIMENTO E TRADIÇÕES DE}

PESQUISA NA FACULDADE DE FILOSOFIA, CIÊNCIAS E

\section{LETRAS - USP (1934-1968)}

MÁRCIA REGINA BARROS DA SILVA, MARIA AMÉLIA MASCARENHAS DANTES

\section{RESUMO}

O objetivo deste artigo é apresentar os primeiros resultados do projeto Memória científica e acadêmica: preservação documental da Faculdade de Filosofia, Ciências e Letras da USP (1934-1968), aprovado no Edital Memória USP 2012, da Pró-reitoria de Cultura e Extensão. Tal projeto pretende caracterizar tradições de pesquisa presentes nas primeiras décadas da Faculdade de Filosofia, Ciências e Letras da USP, criada em 1934, até a reforma universitária de 1969. A proposta está centrada na análise das teses e dissertações que foram orientadas e defendidas nas várias áreas científicas que compunham a faculdade, por meio da busca do que chamamos de 'genealogias científicas', uma forma de acompanhar os docentes orientadores e seus alunos. Desta maneira busca-se verificar os alunos que permaneceram na universidade e, que por sua vez, também se tornaram orientadores em suas respectivas áreas.

PALAVRAS-CHAVE

História da ciência. Universidade de São Paulo. Patrimônio cultural. 


\title{
PRODUCTION OF KNOWLEDGE AND RESEARCH TRADITIONS IN THE FACULTY OF PHILOSOPHY, SCIENCES AND LETTERS - USP (1934-1968) \\ MÁRCIA REGINA BARROS DA SILVA, MARIA AMÉLIA MASCARENHAS DANTES
}

\begin{abstract}
This paper's objective is to present the first results obtained by the Scientific and Academic Memory: Document Preservation of Faculty of Philosophy, Sciences and Letters of USP (1934-1968) project, approved in USP Memory Notice 2012, by the Culture and Extension rectory. This project aims to characterize the research traditions from the first decades of the Faculty of Philosophy, Sciences and Letters, created in 1934, to the university reform of 1969. This article presents the analysis of different theses and dissertations presented on the faculty's various scientific fields, after the search for what we call "scientific genealogies", a way to track the guiding teachers and their students. This way, we intend to see which students remained at the university and, in turn, have become mentors in their respective fields.
\end{abstract}

KEYWORDS

History of science. Universidade de São Paulo. Cultural heritage. 


\section{INTRODUÇÃO}

A Faculdade de Filosofia, Ciências e Letras (FFCL), criada em 1934 para compor a nova Universidade de São Paulo, sediou, até 1968, o ensino e a pesquisa em diferentes áreas. Seus cursos, de acordo com o primeiro relatório institucional da faculdade ${ }^{1}$, eram divididos em três seções, que tinham a seguinte composição (Tabela 1):

TABELA 1

Seções e subseções. Fonte: FFLCHUSP. ANUÁRIOS

da Faculdade de Filosofia, Ciências e Letras. Universidade de São Paulo. Vol. 1934-1935. Reimpressão. São Paulo: FFLCH-USP, 2009.

\begin{tabular}{|c|c|c|}
\hline \multicolumn{3}{|r|}{ Seções e Subseções } \\
\hline 1a. Seção & Filosofia & Filosofia \\
\hline \multirow[t]{6}{*}{$2^{a}$. Seção } & Ciências & 1ª. Subseção Ciências Matemáticas \\
\hline & & $2^{\mathrm{a}}$. Subseção Ciências Físicas \\
\hline & & 3a. Subseção Ciências Químicas \\
\hline & & 4a. Subseção Ciências Naturais \\
\hline & & $5^{\text {a }}$. Subseção Geografia e História \\
\hline & & 6a. Subseção Ciências Sociais e Políticas \\
\hline \multirow[t]{2}{*}{$3^{a}$. Seção } & Letras & 1ª. Subseção Letras Clássicas e Português \\
\hline & & 2a. Subseção Línguas Estrangeiras \\
\hline
\end{tabular}

1. Anuário FFCL, 1934-1935. 
Essa composição passou por algumas reestruturações, até ser finalmente alterada com a Reforma Universitária no final dos anos 1960. É possível acompanhar durante esse intervalo, além do início dos diferentes cursos, também atividades de pesquisa e a implantação do sistema de pós-graduação em diferentes áreas. Em linhas gerais, o presente artigo busca apresentar os primeiros resultados do projeto em andamento intitulado "Memória científica e acadêmica: preservação documental da Faculdade de Filosofia, Ciências e Letras da USP (1934-1968)", aprovado no Edital Memória 2012, realizado pela Pró-reitoria de Cultura e Extensão Universitária da USP.

O objetivo do projeto é acompanhar as atividades de pesquisa realizadas na FFCL a partir de sua criação, e mais especificamente desde a primeira dissertação de doutorado, defendida em 1942, até o momento da Reforma Universitária, em 1968. Tal acompanhamento foi iniciado com o levantamento exaustivo das primeiras teses e dissertações que constituem parte importante do acervo histórico da USP, ainda pouco explorado, tendo em vista as possibilidades que representa para a compreensão da organização da produção científica na Universidade de São Paulo naquele período.

Para tanto, foram levantadas e organizadas as informações contidas no acervo do Centro de Apoio à Pesquisa Histórica Sérgio Buarque de Holanda (CAPH), do Departamento de História da atual Faculdade de Filosofia, Letras e Ciências Humanas (FFLCH), além do banco de dados da seção de pós-graduação e de bibliotecas das várias unidades da USP. ${ }^{2}$

Um primeiro levantamento sobre esse material foi publicado em $1977^{3}$, nele, porém, foram referidos apenas os trabalhos publicados nas áreas das ciências humanas. $\mathrm{O}$ atual projeto incluiu teses e dissertações produzidas em todas as áreas, seções e subseções da Faculdade, além de teses de cátedra e de livre docência produzidas no mesmo período. Apesar de estas últimas apresentarem relação mais direta com a carreira docente, não deixam, porém, de indicar as áreas de pesquisa em que os docentes estiveram envolvidos durante a carreira dentro da USP.

2. O CAPH atualmente é depositário das teses e dissertações defendidas na FFLCH, incluindo ainda teses de cátedra e de livre docência. Os institutos criados após a reforma universitária são também depositários de parte das teses e dissertações referentes às diferentes cadeiras da faculdade, que podem também ser encontradas nas bibliotecas dos respectivos institutos. O CAPH centraliza também documentação sobre a antiga FFCL, assim como memoriais e documentação iconográfica diversa. 3. Boletim especial da FFLCH-USP, 1977, levantamento de teses e dissertações de 1939 a 1977. 
TABELA 2

Doutoramentos 1942. BANCO DE

DADOS projeto

Memória científica e acadêmica: preserva-

ção documental

da Faculdade de

Filosofia, Ciências

e Letras da USP

(1934-1968)

\begin{tabular}{|c|c|c|}
\hline Título & Orientando & Orientador \\
\hline $\begin{array}{l}\text { O comércio português no Rio da Prata } \\
(1580-1640)\end{array}$ & Alice Piffer Canabrava & $\begin{array}{l}\text { Jean Gagé - História da } \\
\text { civilização americana }\end{array}$ \\
\hline A segunda parte do Ajax de Sófocles & Aluízio de Faria Coimbra & $\begin{array}{l}\text { Jean Gagé1 - História } \\
\text { Geral }\end{array}$ \\
\hline $\begin{array}{l}\text { As condições geográficas da circulação: } \\
\text { o exemplo brasileiro }\end{array}$ & Antonietta de Paula Souza & Pierre Monbeig Geografia \\
\hline Geografia - ensino e pedagogia & Aroldo Edgard de Azevedo & $\begin{array}{l}\text { Pierre Monbeig } \\
\text { - Geografia }\end{array}$ \\
\hline $\begin{array}{l}\text { As encomiendas e a política colonial da } \\
\text { Espanha }\end{array}$ & Astrogildo Rodrigues de Mello & Jean Gagé - História \\
\hline $\begin{array}{l}\text { Sobre a regularidade dos funcionais } \\
\text { definidos no campo das funções } \\
\text { localmente analíticas }\end{array}$ & Cândido Lima da Silva Dias & $\begin{array}{l}\text { Omar Catunda } \\
\text { - Matemática }\end{array}$ \\
\hline $\begin{array}{l}\text { Introdução ao estudo de alguns proble- } \\
\text { mas metodológicos da psicologia }\end{array}$ & Cícero Christiano de Souza & $\begin{array}{l}\text { Jean Gagé - ou Maugué } \\
\text { Filosofia }\end{array}$ \\
\hline $\begin{array}{l}\text { A concentração demográfica nos } \\
\text { diversos estados do Brasil }\end{array}$ & Eduardo Alcântara de Oliveira & $\begin{array}{l}\text { Milton da Silva Rodrigues } \\
\text { - Estatística }\end{array}$ \\
\hline $\begin{array}{l}\text { O comércio varegue e o Grão } \\
\text { Principado de Kiev }\end{array}$ & Eurípedes Simões de Paula & $\begin{array}{l}\text { Jean Maugué - História } \\
\text { da Civilização Antiga e } \\
\text { Medieval }\end{array}$ \\
\hline $\begin{array}{l}\text { Estudo sobre sistemas binários } \\
\text { orgânicos }\end{array}$ & Francisco Berti & Paul Arbousse Bastide \\
\hline $\begin{array}{l}\text { Sobre o Cafesterol e alguns dos seus } \\
\text { derivados }\end{array}$ & Jandyra França Barzaghi & $\begin{array}{l}\text { Heinrich Hauptman } \\
\text { - Química }\end{array}$ \\
\hline $\begin{array}{l}\text { Ensaio sobre a vida e a obra do filósofo } \\
\text { Francisco Sanchez }\end{array}$ & João Cruz Costa & Jean Maugué - Filosofia \\
\hline $\begin{array}{l}\text { Ensaio sobre a significação e importân- } \\
\text { cia da memória sobre a reforma dos } \\
\text { estudos da Capitania de São Paulo, } \\
\text { escrita em } 1816 \text { por Martin Francisco } \\
\text { Ribeiro de Andrade Machado }\end{array}$ & José Quirino Ribeiro & $\begin{array}{l}\text { Alfredo Ellis Júnior } \\
\text { - História }\end{array}$ \\
\hline $\begin{array}{l}\text { Alguns aspectos atuais do problema do } \\
\text { método objetivo e divisões da Ciência } \\
\text { Política }\end{array}$ & Lourival Gomes Machado & $\begin{array}{l}\text { Paul Arbousse Bastide } \\
\text { - Sociologia }\end{array}$ \\
\hline $\begin{array}{l}\text { A poesia compensatória de Amadeu do } \\
\text { Amaral }\end{array}$ & Manoel Cerqueira Leite & Sem informação. Letras \\
\hline $\begin{array}{l}\text { Estudo das formas de colonização e } \\
\text { povoamento nos estados do Paraná, } \\
\text { Santa Catarina e Rio Grande do Sul }\end{array}$ & Maria Stella Guimarães & $\begin{array}{l}\text { Sem informação. } \\
\text { Geografia }\end{array}$ \\
\hline Sobre a cloaca do Siphonops & Michel Pedro Sawaya & $\begin{array}{l}\text { Ernest Marcus - Ciências } \\
\text { Sociais e Políticas }\end{array}$ \\
\hline Sobre a natureza dos ácidos coléicos & $\begin{array}{l}\text { Paschoal Ernesto Américo } \\
\text { Senise }\end{array}$ & $\begin{array}{l}\text { Heinrich Rheinboldt } \\
\text { - Química }\end{array}$ \\
\hline $\begin{array}{l}\text { Sobre mercaptanas bivalentes e } \\
\text { sulfeto-dimercaptanas }\end{array}$ & Simão Mathias & $\begin{array}{l}\text { Heinrich Rheinboldt } \\
\text { - Química }\end{array}$ \\
\hline
\end{tabular}




\section{AS TESES E A REALIZAÇÃO DE PESQUISA NA FFCL DA USP}

No decreto de criação da USP já havia indicação de realização de pesquisa entre os objetivos da universidade, porém sua organização mais detalhada seria pelo Decreto Estadual n. 12.038 de 01/07/1941, que aprovava o Regulamento da FFCL, no qual diploma e título de doutor eram regulamentados.

Esse decreto tornou obrigatória a realização dos doutoramentos pelos assistentes contratados, que teriam a partir dali prazo de dois a três anos, com a obrigatoriedade de frequência em duas disciplinas específicas, para obterem seus títulos ${ }^{4}$. Aqueles que já fossem catedráticos receberiam automaticamente o título de doutor 5 .

Após essa regulamentação, rapidamente começaram a ser apresentadas as primeiras teses da FFCL. No ano de 1942, 18 doutoramentos foram defendidos (Tabela 2).

O regimento interno votado pela Congregação da Faculdade em 9 de dezembro de $1941^{7}$ tinha 15 artigos e previa quatro tipos de títulos: doutor em filosofia, doutor em ciências, doutor em letras e doutor em pedagogia. Deveria ser mencionado ainda no diploma o curso ao qual a matéria da tese se referia, sendo que aqueles que já atuavam como assistentes poderiam requerer o exame e a defesa em apenas um ano, depois de avaliação do Conselho Técnico Administrativo da Universidade.

Atividades de formação e pesquisa como seminários e publicações já haviam sido iniciadas pelos catedráticos desde os primeiros anos da

4. Art. 42 - Os assistentes de qualquer cadeira da Faculdade de Filosofia, Ciências e Letras que não tiverem obtido dentro do prazo máximo de três anos, a contar da data da sua nomeação, o diploma de doutor, perderão automaticamente o cargo para o qual foram nomeados. Art. 75 - Os atuais assistentes de qualquer categoria, que não forem bacharéis, serão mantidos em seus cargos enquanto bem servirem, devendo, porém, obter o diploma de doutor dentro de dois anos a partir da data da publicação desta lei. Decreto n. 12.038, de 1. ${ }^{\circ}$ de julho de 1941. Disponível em: <http://www.al.sp. gov.br/repositorio/legislacao/decreto/1941/decreto-12038-01.07.1941.html> Acessado em 05 set. 2014. 5. Art. $60 . \$ 1 .^{\circ}-$ Será conferido o diploma de doutor ao bacharel que defender tese de notável valor, depois de dois anos, pelo menos, de estudos, sob a orientação do professor catedrático da disciplina sobre que versar os seus trabalhos, e for aprovado no exame de duas disciplinas subsidiárias da mesma secção ou de secção afim àquela em que for defendida a tese. $\$ 2 .^{\circ}{ }^{-}$- Será concedido o título de doutor igualmente a todos os aprovados em concurso para catedrático, bem como aos atuais catedráticos da Faculdade que tenham sido aprovados em defesa de tese, no concurso prestado. $\$$ $3 .^{\circ}$ - O regulamento interno da Faculdade disporá sobre a forma da concessão do diploma de doutor. Decreto n. 12.038, de 1. ${ }^{\circ}$ de julho de 1941. Disponível em: <http://www.al.sp.gov.br/repositorio/ legislacao/decreto/1941/decreto-12038-01.07.1941.html> Acessado em 05 set. 2014

6. Catedrático de História geral de 1938 a 1941, e de História moderna e contemporânea de 1941 a 1946. 7. GUIA. Guia. Faculdade de Filosofia, Ciências e Letras da Universidade de São Paulo, 1943. 
faculdade. Neste sentido o mesmo decreto indicava ainda as cadeiras que deveriam manter regime de tempo integral ${ }^{8}$, denotando claramente a ocorrência de atividades de pesquisa dentro da FFCL, tanto em laboratórios quando em pesquisas de campo'.

Nos anos iniciais da Faculdade foram contratados professores estrangeiros como docentes para diversas cadeiras, no entanto, a atuação destes professores na orientação de teses e na formação de novos pesquisadores em suas áreas foi diferente, tendo em vista seu envolvimento com a pesquisa e de acordo com as características de cada área, além do tempo de permanência do docente nos quadros da FFCL. Teses de doutoramento e dissertações tiveram distribuição e representatividade bastante diversificada em todo o período abarcado por este projeto. Houve mais de 500 defesas, entre teses e dissertações de doutorado, além de cerca 200 volumes que indicam defesas de concursos de livre-docência e de cátedra.

Após o primeiro decreto, de 1948, a composição das sessões e subseções foi sendo modificada até a criação dos departamentos, a partir de 1968. A reforma universitária instituída pelo governo federal por meio da Lei $\mathrm{n}$. 5.540, teve o Decreto Estadual n. 52.326, de 16/12/1969, aprovando o estatuto de implantação da reforma universitária na USP, o que marcou também a dissolução da antiga FFCL, que foi reorganizada com nova composição. A partir das áreas da antiga faculdade foram definidos novos cursos de graduação e criados diferentes institutos, dando nova delimitação àquela faculdade.

Não será objeto do presente artigo a discussão desse processo, que nos serviu de limite, já que o novo arranjo adotado fixou como unidades distintas os cursos de humanidades e os de ciências, que haviam funcionado juntos na antiga FFCL, criando em separado a nova Faculdade de Filosofia, Letras e Ciências Humanas e os respectivos institutos de Física,

\footnotetext{
8. Art. 28 - Serão mantidas no regime de tempo integral as seguintes cadeiras: a) Física Geral e Experimental (XII cadeira); b) Física Teórica e Física Matemática (XIII cadeira); c) Química Geral e Inorgânica e Química Analítica (XIV cadeira); d) Química Orgânica e Química Biológica (XV cadeira); e) Biologia Geral (XVII cadeira); f) Zoologia (XVIII cadeira); g) Botânica (XX cadeira); h) Fisiologia Geral e Animal (XIX cadeira); i) Geologia e Paleontologia (XXI cadeira); j) Mineralogia e Petrografia (XXII cadeira); k) Etnografia e Língua Tupi-guarani (XXIX cadeira). Decreto n. 12.038, de 1. ${ }^{\circ}$ de julho de 1941. 9. Parágrafo único - Afim de atender às necessidades da pesquisa experimental ou documentária, bem como da direção dos estudos de especialização e doutoramento, as demais cadeiras da Faculdade de Filosofia. Ciências e Letras serão gradualmente, na medida das necessidades de cada uma, mediante aprovação do Governo do Estado, postas em regime de tempo integral por proposta da Congregação. Decreto n. 12.038, de 1. . de julho de 1941.
} 
de Biociências, de Geociências, de Matemática e Estatística, de Química, de Psicologia e a Faculdade de Educação.

Demos destaque nesta fase da pesquisa à identificação dos dados referentes a cada tese e dissertação, entre autoria, título, cadeira e localização física, pois esses materiais não se encontram em um único acervo, o que causa divergência na totalização dos dados.

Esta fase inicial foi realizada a partir do cruzamento de bancos de dados das diferentes bibliotecas da USP e na consulta física a cada exemplar existente, a fim de possibilitar a conferência das informações acima indicadas, assim como o estado de conservação do material e o reconhecimento das características específicas de cada volume em determinada área. Na segunda fase da pesquisa poderá ser avaliada a presença de resumo, índice, apresentação, bibliografia. Além dessas informações básicas, foi possível verificar a presença de anexos específicos, como fotografias de pesquisas de campo, reprodução fotográfica de resultados de leitura de instrumentos, uso crescente de equipamentos e reprodução cada vez maior de dados comparativos. Tais dados serão confrontados com análise sobre os conteúdos de teses e dissertações nas diferentes áreas.

Nosso objetivo neste artigo é apresentar, de modo panorâmico, o conjunto mais geral dessa produção. Nossa intenção maior é proceder à futura análise sobre a formação de tradições de pesquisa e sobre a temática desenvolvida em cada área, por meio de um conjunto de pesquisadores que estão já encaminhando análise para as diferentes áreas da faculdade, em suas respectivas genealogias científicas. O principal resultado desta primeira etapa da pesquisa foi a reunião, em um único banco de dados, das informações parciais existentes em diferentes bibliotecas da USP, o que confere maior qualidade à identificação de temas, corpo discente e docente na história da Universidade naquele momento.

\section{GENEALOGIAS CIENTÍFICAS}

$\mathrm{O}$ ordenamento das orientações dos primeiros professores e das teses e dissertações por eles orientadas evidencia como foram se constituindo as primeiras linhas de pesquisa na faculdade. Mostra também que um número significativo dos primeiros alunos de pós-graduação se tornaram docentes da FFCL e, em sua grande maioria, que eles permaneceram como docentes da FFLCH após a reforma de 1969. 
É neste sentido que o acompanhamento das teses e dissertações tem sido realizado, com o fim de fornecer os dados iniciais para o que chamamos de "genealogias científicas", uma forma de acompanhar os docentes orientadores e seus alunos de modo a verificar aqueles alunos que permaneceram na universidade e que, por sua vez, também se tornaram orientadores em suas respectivas áreas. Por vezes é possível verificar que o orientando foi também aluno de graduação dos cursos da própria faculdade, o que os fazia permanecer por um longo período na instituição.

Apesar de essas informações serem de conhecimento coletivo, elas não haviam sido totalizadas até o momento. Por isso, o presente artigo possibilita acompanhar comparativamente o conjunto de defesas por ano, área e orientador, e, além disso, permite também verificar quais catedráticos tiveram maior conjunto de orientandos sob sua responsabilidade e aqueles que não se dedicaram a orientações. Pelos títulos dos trabalhos defendidos se verifica as temáticas em que se iniciaram as pesquisas na faculdade e em quais delas os novos doutores e mestres se desenvolveram como novos orientadores de outros pesquisadores, criando espaço para o crescimento da pesquisa científica na universidade.

Vejamos a seguir como foram se organizando as genealogias nas diferentes áreas do conhecimento da Faculdade de Filosofia, Letras e Ciências, que serão apresentadas segundo essa ordem. Dentro do período estudado foi possível verificar quais catedráticos iniciaram programas de pós-graduação com orientação de assistentes que, em diversos casos, vieram a se constituir na primeira geração de doutores e mestres, estes em menor número, que por sua vez passaram também a orientar projetos de pesquisas.

\section{SEÇÃO DE FILOSOFIA}

Étienne Borne, primeiro contratado para o ensino de filosofia, permaneceu pouco tempo no Brasil, sendo substituído por Jean Maugué em 1935. Seguindo o modelo de ensino francês, a seção sediava estudos de filosofia e psicologia, esta dedicada aos estudos da mente.

Foi Jean Maugué quem deu início à orientação na área de filosofia. Entre 1942 e 1946 foram defendidas quatro teses pelos primeiros assistentes da cadeira: João Cruz Costa, que viria a substituir Maugué na regência da cadeira de filosofia geral; Lívio Teixeira; Cícero Christiano de Souza, que viria a atuar 


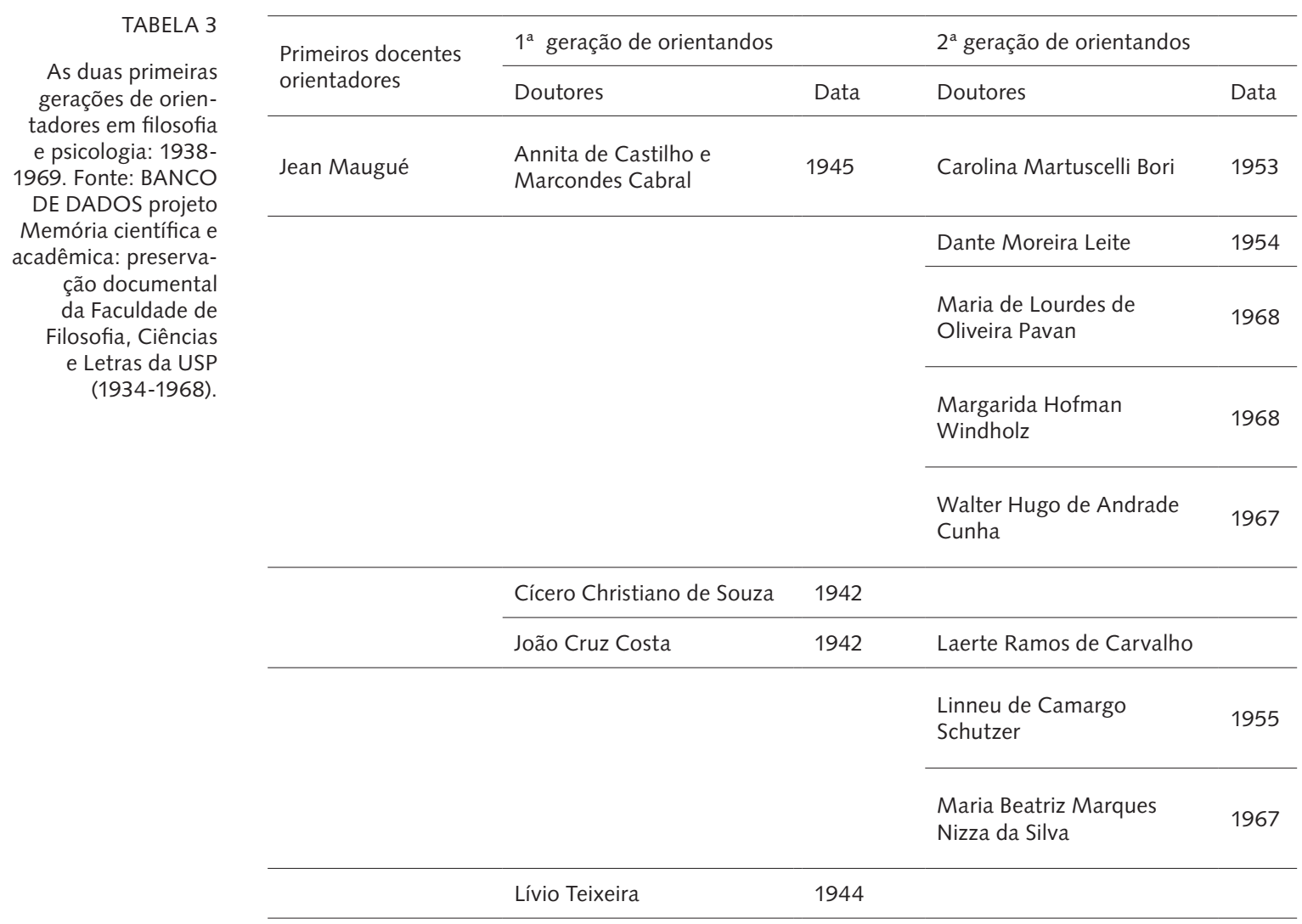

na área da psicologia; Annita de Castilho Marcondes Cabral, que atuava nessa mesma área e que teve papel importante na implantação da psicologia na USP.

Mais tarde outros professores estrangeiros também vieram a se destacar: Gilles Gaston Granger, que lecionou em dois períodos, de 1947 a 1952 e em 1960, e orientou a tese de doutorado de José Arthur Giannotti em 1960; Claude Lefort que lecionou no ano de 1953; Michel Debrun, que permaneceu na faculdade de 1960 a 1965; e Gerard Lebrun, docente de 1961 a 1965.

Até os anos 1960 a cátedra de filosofia teve poucos doutoramentos, já no período de 1967 a 1969 foram defendidos outros quatro doutorados e quatro mestrados.

A área da psicologia que, naquele momento, pertencia à Seção de Filosofia, foi a que mais cresceu no período, e nos anos 1950 começava a se separar da filosofia. Em 1953 foi aprovado pela Congregação da FFLC um curso independente de psicologia e, em 1957, pela lei n. 3.862 de 28 de maio, foi criado o curso de psicologia, que começou a funcionar em 1958. 
O primeiro doutoramento que tratou de tema da área da psicologia foi o de Annita de Castilho Marcondes Cabral, em 1945, orientada por Jean Maugué e Roger Bastide, professor catedrático da subseção de sociologia. Annita Cabral viria a ser a primeira orientadora do departamento de psicologia e também a primeira mulher a orientar dentro da FFCL. A partir de 1953 ela passou a formar vários assistentes que também se destacaram em suas respectivas carreiras, entre eles, Carolina Bori, que passou a orientar em 1968.

\section{SEÇÃO DE CIÊNCIAS}

A Seção de Ciências da FFCL da USP era bastante ampla, incluindo tanto as ciências humanas e sociais, como as ciências exatas e da natureza. Essa seção foi também bastante diversificada em relação ao conjunto de professores estrangeiros contratados. Para as áreas de matemática, física e mineralogia, vieram professores italianos; para química, e a maior parte das cadeiras de história natural, foram contratados professores alemães. Ainda em ciências, as subseções de história e geografia e ciências sociais e políticas tiveram suas atividades efetivadas por professores franceses.

Alguns dos primeiros professores estrangeiros permaneceram por muitos anos no Brasil e foram responsáveis pela formação da primeira geração de pesquisadores paulistas. Nesta condição, destaque para Heinrich Rheinboldt e Heinrich Hauptmann, que atuaram em físico-química e química orgânica, respectivamente. Em botânica, Felix Rawitscher também atuou por muitos anos, e em zoologia Ernst Marcus foi o mais destacado, tendo sido contratado após a morte prematura de Ernest Bresslau. $\mathrm{Na}$ área da geologia, o professor estrangeiro que mais se destacou na orientação de teses foi Victor Leinz, que, no entanto, só foi contratado em 1948.

Entre os professores italianos, aquele que teve presença mais marcante na implantação de atividades de pesquisa foi Gleb Wataghin, catedrático de física, que permaneceu no Brasil até 1949. Entre os franceses, destacaram-se na orientação de doutoramentos: em geografia, Pierre Monbeig, que substituiu Pierre Deffontaines; Paul Arbousse-Bastide, que atuou em ciências políticas; Jean Gagé, da cátedra de história, que substituiu Émile Coornaert. Em sociologia, teve destaque Roger Bastide, e em antropologia, Emilio Willens. Na mesma década, Paul Hugon, catedrático de economia, foi um dos mais atuantes. 
Apesar da forte presença de professores estrangeiros - que nos primeiros anos foram os principais responsáveis pelas atividades de ensino e pesquisa nas várias Seções -, merecem destaque também alguns professores e assistentes brasileiros. Um número significativo de brasileiros atuou, sobretudo, na parte didática, mas alguns deles também se destacaram na orientação de teses. Em sociologia, Fernando de Azevedo, um dos fundadores da USP; em matemática, Omar Catunda, o primeiro orientador na área; em ciências biológicas, André Dreyfus, que teve ação destacada na implantação da genética, e Paulo Sawaya, o primeiro a orientar em fisiologia; em geologia, Reynaldo Saldanha da Gama.

\section{SUBSEÇÃO DE MATEMÁTICA}

Os professores contratados para esta subseção - Luigi Fantappié e Giacomo Albanesi - logo retornaram para a Itália. O primeiro orientador foi, portanto, o novo professor contratado nesta área, Omar Catunda, catedrático desde 1944. Alguns de seus assistentes fizeram carreira na USP e deram início a novas linhas de pesquisa: Cândido Lima da Silva Dias, doutor em

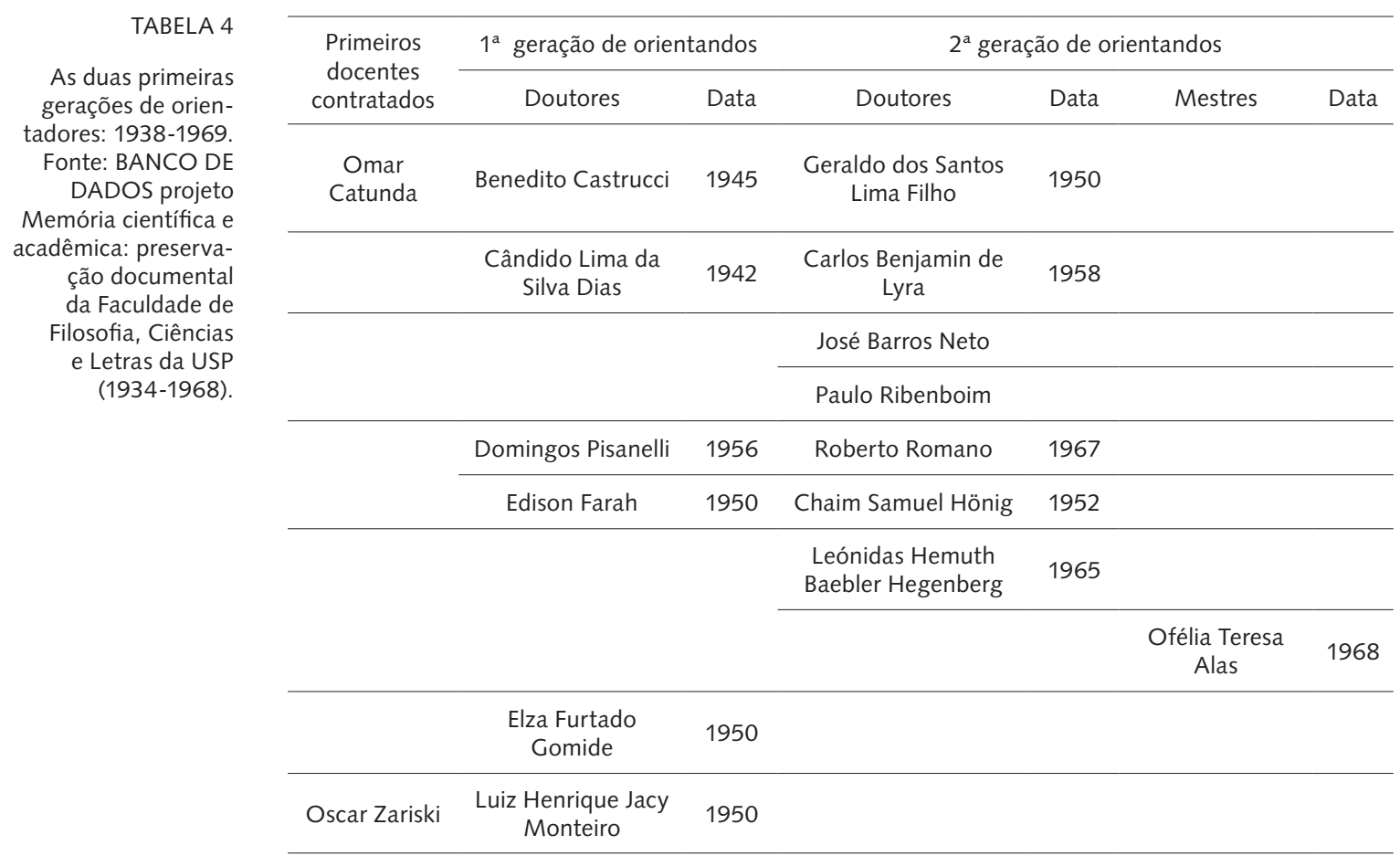


1942; Benedito Castrucci, doutor em 1945; e, nos anos 1950, Elza Gomide, Edison Farah e Domingos Pisanelli. Mas o número de doutorados na área da matemática foi relativamente baixo, só se ampliando nos anos 1960.

Nos anos 1940 foram contratados novos professores estrangeiros para a matemática, com destaque para os pesquisadores do grupo Bourbaki. Também foi contratado Oscar Zariski, especialista em geometria algébrica e que foi orientador do doutoramento de Jacy Monteiro, que fez carreira na USP.

\section{SUBSEÇÃO DE FÍSICA}

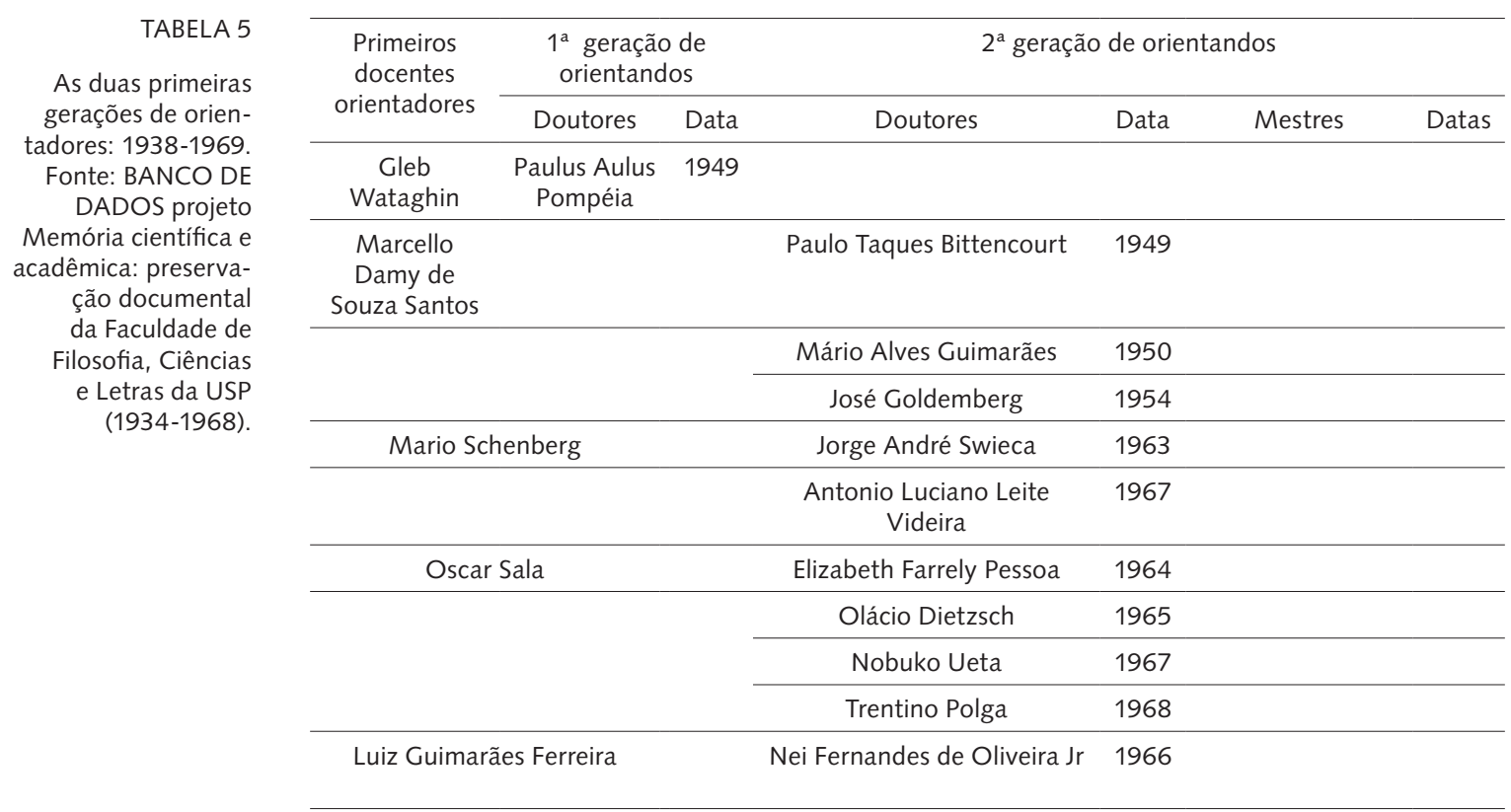


Gleb Wataghin, contratado para esta subseção, foi bastante ativo, tendo montado o primeiro laboratório brasileiro de raios cósmicos, que já nos anos 1940 era conhecido internacionalmente. Introduziu assim seus alunos na pesquisa e bibliografia atualizada. Trouxe para a USP outro pesquisador italiano, Giuseppe Occhialini, que também atuou em física experimental. Mas Wataghin só orientou uma tese de doutoramento na USP, pois enviava seus alunos para o doutoramento no exterior. Em 1949, foi defendida por Paulus A. Pompéia a primeira tese em física da FFCL.

Foram alguns dos primeiros alunos de Wataghin que deram início à orientação de teses em física na USP. Mário Schenberg, físico teórico e catedrático em 1944, passou a orientar teses nos anos 1960; Marcello Damy de Souza Santos, físico experimental, catedrático em 1945, diretor da equipe do acelerador Bétraton, começou a formar físicos experimentais - como José Goldemberg e Elly Silva, entre outros.

Também merece destaque Oscar Sala, que atuou em física nuclear, tendo sido diretor do acelerador Van de Graaff, e orientou várias teses como a de Olácio Dietzsch e Elisabeth Frota-Pessoa, entre outros.

O número de doutoramentos em física só se ampliou nos anos 1960, com a atuação de uma nova geração de físicos, como José Goldemberg e Luís Guimarães Ferreira.

\section{SUBSEÇÃO DE QUÍMICA}

Heinrich Rheinboldt, primeiro catedrático da química, e depois Heinrich Hauptmann, catedrático em 1946, se dedicaram bastante à orientação de doutoramentos. Nos anos 1940 formaram-se cerca de 15 doutores, dos quais pelo menos seis se tornaram professores da USP. Rheinboldt orientou pesquisas em físico-química e teve três alunos que defenderam teses em 1942: Simão Mathias, Paschoal Ernesto A. Senise e Francisco Berti. Em 1946, Giuseppe Cilento tornou-se doutor. Foram químicos que depois se destacaram na orientação de teses. Rheinboldt continuou orientando até 1957.

Hauptmann, que trabalhava em química orgânica, orientou a tese de Jandyra do Amaral, a primeira mulher a defender tese de doutoramento na USP, em 1942. Hauptmann ainda estava ativo nos anos 1960 e, entre seus alunos, merece destaque Blanka Werteim Wladislaw, doutora em 1949, que fez carreira na USP. 
TABELA 6

As duas primeiras gerações de orientadores: 1938-1969.

Fonte: BANCO DE DADOS projeto Memória científica e acadêmica: preservação documental da Faculdade de Filosofia, Ciências e Letras da USP (1934-1968)

\begin{tabular}{|c|c|c|c|c|}
\hline \multirow{2}{*}{$\begin{array}{c}\text { Primeiros } \\
\text { docentes } \\
\text { orientadores }\end{array}$} & \multicolumn{2}{|c|}{$1^{a}$ geração de orientandos } & \multicolumn{2}{|l|}{$2^{a}$ geração de orientandos } \\
\hline & Doutores & Data & Doutores & Data \\
\hline \multirow{24}{*}{$\begin{array}{l}\text { Heinrich } \\
\text { Rheinboldt }\end{array}$} & Alfredo Levy & 1948 & & \\
\hline & Ernesto Giesbrecht & 1947 & Oswaldo Antonio Serra & 1969 \\
\hline & Francisco Berti & 1942 & & \\
\hline & Geraldo Vicentini & 1957 & & \\
\hline & Gerninio Nazano & 1946 & & \\
\hline & Giuseppe Cilento & 1946 & Divo Leonardo Sanioto & 1966 \\
\hline & & & Klaus Zinner & 1967 \\
\hline & & & Marcos Berenholc & 1967 \\
\hline & & & Shirley Schreier & 1969 \\
\hline & & & Aurora C. Gior Albanese & 1961 \\
\hline & $\begin{array}{l}\text { Luiz Roberto de Moraes } \\
\text { Pitombo }\end{array}$ & 1954 & & \\
\hline & Madeleine Perrier & 1947 & & \\
\hline & $\begin{array}{l}\text { Marco Antonio Gugliermo } \\
\text { Cecchini }\end{array}$ & 1952 & & \\
\hline & Nicoló Petragnani & 1956 & & \\
\hline & $\begin{array}{l}\text { Paschoal Ernesto Américo } \\
\text { Senise }\end{array}$ & 1942 & Eduardo Fausto de Almeida Neves & 1965 \\
\hline & & & Franco Levi & 1965 \\
\hline & & & Oswaldo Espírito Santo Godinho & 1969 \\
\hline & & & Rêmolo Ciola & 1961 \\
\hline & & & Lilia Rosária Sant'Agostinho & 1959 \\
\hline & Simão Mathias & 1942 & Eurico de Carvalho Filho & 1959 \\
\hline & & & Renato Giovanni Cecchini & 1962 \\
\hline & Waldemar Safiotti & 1948 & & \\
\hline & Waldomiro Pregnolatto & 1946 & & \\
\hline & Walter Loewenstein & 1948 & & \\
\hline \multirow{13}{*}{$\begin{array}{l}\text { Henrich } \\
\text { Hauptmann }\end{array}$} & Augusto Cid Mello Perissé & 1957 & & \\
\hline & Aurora Giora & 1961 & & \\
\hline & Blanka Wertheim & 1949 & Hans Viertler & 1969 \\
\hline & & & João Pedro Zimmermann & 1969 \\
\hline & Cyro Marino & 1963 & & \\
\hline & Hanna Augusta Rothschild & 1948 & & \\
\hline & Horst Berl & 1958 & & \\
\hline & Jandyra França Barzaghi & 1942 & & \\
\hline & Lucy Lacerda Bruck Nazario & 1948 & & \\
\hline & Marcello de Moura Campos & 1950 & & \\
\hline & Paulo Ana Bobbio & 1960 & & \\
\hline & Rainer Fried & 1952 & & \\
\hline & Wolfgang Ferdinand Walter & 1955 & & \\
\hline
\end{tabular}




\section{SUBSEÇÃO DE HISTÓRIA NATURAL}

Esta subseção compreendia um conjunto diversificado de áreas e recebeu especialistas, em geral alemães, para regerem as cátedras.

\section{Botânica}

\begin{tabular}{|c|c|c|c|c|c|c|c|c|}
\hline \multirow{6}{*}{$\begin{array}{r}\text { TABELA } 7 \\
\text { As duas primeiras } \\
\text { gerações de orien- } \\
\text { tadores: 1938-1969. } \\
\text { Fonte: BANCO DE } \\
\text { DADOS projeto } \\
\text { Memória científica e } \\
\text { acadêmica: preserva- } \\
\text { ção documental } \\
\text { da Faculdade de } \\
\text { Filosofia, Ciências } \\
\text { e Letras da USP } \\
\text { (1934-1968). }\end{array}$} & \multirow{3}{*}{$\begin{array}{c}\begin{array}{c}\text { Primeiros } \\
\text { docentes } \\
\text { orientadores }\end{array} \\
\text { Felix Rawitscher }\end{array}$} & \multicolumn{3}{|c|}{$1^{a}$ geração de orientandos } & \multicolumn{4}{|c|}{$2^{\mathrm{a}}$ geração de orientandos } \\
\hline & & \multirow{2}{*}{$\begin{array}{c}\text { Doutores } \\
\begin{array}{c}\text { Aylthon } \\
\text { Brandão Joly }\end{array}\end{array}$} & \multicolumn{2}{|l|}{ Data } & \multirow{2}{*}{$\begin{array}{c}\text { Doutores } \\
\text { Eurico Cabral } \\
\text { de Oliveira } \\
\text { Filho }\end{array}$} & \multirow{2}{*}{$\begin{array}{l}\text { Data } \\
1967\end{array}$} & \multirow[t]{2}{*}{ Mestres } & \multirow[t]{2}{*}{ Datas } \\
\hline & & & 1949 & & & & & \\
\hline & & & & & $\begin{array}{c}\text { Kurt Cünther } \\
\text { Hell }\end{array}$ & 1967 & & \\
\hline & & & & & Clóvis Teixeira & 1969 & & \\
\hline & & & & & & & $\begin{array}{c}\text { Margarida } \\
\text { Maria Barros }\end{array}$ & 1969 \\
\hline & & $\begin{array}{l}\text { Berta Lange } \\
\text { de Morretes }\end{array}$ & 1948 & & & & $\begin{array}{c}\text { Idene de } \\
\text { Jesus Teixeira } \\
\text { Eiten }\end{array}$ & 1969 \\
\hline & & & & & & & $\begin{array}{l}\text { Liene de Jesus } \\
\text { Teixeira Eiten }\end{array}$ & 1969 \\
\hline & & & & & & & $\begin{array}{l}\text { Maria Lea } \\
\text { Salgado } \\
\text { Labourian }\end{array}$ & 1969 \\
\hline & & Erika Anna Lu & tscher & 1948 & & & & \\
\hline & & Mario Guin & erri & 1944 & $\begin{array}{l}\text { Antônio } \\
\text { Lamberti }\end{array}$ & 1966 & & \\
\hline & & & & & $\begin{array}{l}\text { Bernardo } \\
\text { Beiguelman }\end{array}$ & 1961 & & \\
\hline & & & & & $\begin{array}{l}\text { Leopoldo } \\
\text { Magno } \\
\text { Coutinho }\end{array}$ & 1960 & & \\
\hline & & & & & $\begin{array}{l}\text { Maria Amélia } \\
\text { Braga de } \\
\text { Andrade }\end{array}$ & 1964 & & \\
\hline & & & & & $\begin{array}{l}\text { Marico } \\
\text { Meguro }\end{array}$ & 1960 & & \\
\hline & & & & & $\begin{array}{l}\text { Wiktor } \\
\text { Wajntal }\end{array}$ & 1968 & & \\
\hline & & & & & Walter Handro & 1968 & & \\
\hline & & $\begin{array}{l}\text { Mercedes } \\
\text { Rachid }\end{array}$ & 1947 & & & & & \\
\hline
\end{tabular}


Felix Rawitscher, professor contratado para a área de botânica, orientou diversas teses de 1944 a 1949. Alguns de seus alunos se destacaram na USP, como Mário Guimarães Ferri, doutor em 1944, que orientou teses nos anos 1960. Rawitscher também orientou Berta Lange de Morretes, doutora em 1948; e Aylthon Brandão Joly, que também fez carreira na USP, doutorando-se em 1949. Ambos orientaram principalmente nos anos 1960 e 1970. Além desses, também ganhou renome internacional Mercedes Rachid. Nesta área merecem destaque os estudos sobre a flora da caatinga e de outras regiões do território brasileiro.

\section{ZOOLOGIA}

TABELA 8

$$
\begin{array}{r}
\text { As duas primeiras } \\
\text { gerações de orien- } \\
\text { tadores: 1938-1969. } \\
\text { Fonte: BANCO DE } \\
\text { DADOS projeto } \\
\text { Memória científica e } \\
\text { acadêmica: preserva- } \\
\text { ção documental } \\
\text { da Faculdade de } \\
\text { Filosofia, Ciências } \\
\text { e Letras da USP } \\
\text { (1934-1968). }
\end{array}
$$

\begin{tabular}{|c|c|c|c|c|}
\hline \multirow{2}{*}{$\begin{array}{l}\text { Primeiros docentes } \\
\text { orientadores }\end{array}$} & \multicolumn{2}{|c|}{$1^{\text {a }}$ geração de orientandos } & \multicolumn{2}{|c|}{$2^{a}$ geração de orientandos } \\
\hline & Doutores & Data & Doutores & Data \\
\hline \multirow[t]{15}{*}{ Ernest Marcus } & Michel Pedro Sawaya & 1942 & & \\
\hline & Marta Vannucci Mendes & 1945 & & \\
\hline & Edmundo Ferraz Nonato & 1946 & & \\
\hline & Gabriela Zuccari & 1947 & & \\
\hline & Diva Diniz Correa & 1948 & Sérgio de Almeida Rodrigues & 1964 \\
\hline & & & Luiz Dino Vizotto & 1967 \\
\hline & & & Cory Teixeira de Carvalho & 1969 \\
\hline & & & Luiz Roberto Tommasi & 1969 \\
\hline & Claudio Gilberto Froehlich & 1954 & & \\
\hline & Eudoxia Maria Froehlich & 1954 & & \\
\hline & Liliana Forneris & 1958 & $\begin{array}{c}\text { Tagea Kristina Simon } \\
\text { Bjornberg }\end{array}$ & \\
\hline & Gilberto Righi & 1962 & & \\
\hline & Paulo Nogueira Neto & 1963 & & \\
\hline & Plinio Soares Moreira & 1966 & & \\
\hline & Fabio Aranha Matthiesen & 1966 & & \\
\hline
\end{tabular}


Ernest Marcus, catedrático em 1945, foi o professor que mais se destacou na área da zoologia, orientando doutoramentos de 1942 a 1966. Entre seus alunos, Diva Diniz Correa, doutora em 1948, tornou-se professora da USP, tendo orientado mais a partir dos anos 1960. Também Michel Pedro Sawaya permaneceu na USP, sendo doutor em 1942; assim como Liliana Forneris, doutora em 1958.

Entre os alunos de Marcus merece destaque, também, Paulo Nogueira Neto (doutor em 1963), que foi professor da USP e ganhou renome por sua atuação em ecologia, tendo ocupado o cargo de Secretário Especial do Meio Ambiente (1973-1985) no governo federal. Martha Vannucci, aluna de Marcus nos anos 1940, passou a trabalhar com zoologia marinha, sendo professora do Instituto de Oceanografia da USP, ganhando renome internacional com seus estudos sobre mangues. Entre as teses defendidas nesta área, várias foram pesquisas sobre animais existentes no Brasil.

\section{BIOLOGIA GERAL}

TABELA 9

As duas primeiras gerações de orientadores: 1938-1969.

Fonte: BANCO DE DADOS projeto Memória científica e acadêmica: preservação documental da Faculdade de Filosofia, Ciências e Letras da USP (1934-1968).

\begin{tabular}{|c|c|c|c|c|c|c|}
\hline \multirow{2}{*}{$\begin{array}{c}\text { Primeiros } \\
\text { docentes } \\
\text { contratados }\end{array}$} & \multicolumn{2}{|l|}{$\begin{array}{l}1^{\text {a }} \text { geração de } \\
\text { orientandos }\end{array}$} & \multicolumn{3}{|c|}{$2^{\mathrm{a}}$ geração de orientandos } & \multirow[b]{2}{*}{ Data } \\
\hline & Doutores & Data & Doutores & Data & Mestres & \\
\hline \multirow[t]{17}{*}{$\begin{array}{l}\text { André } \\
\text { Dreyfus }\end{array}$} & $\begin{array}{l}\text { Antonio Brito da } \\
\text { Cunha }\end{array}$ & 1948 & Edison Pereira dos Santos & 1968 & & \\
\hline & & & Hamilton João Targa & 1969 & & \\
\hline & & & Hebe Myrina Laghi de Souza & 1969 & & \\
\hline & & & & & $\begin{array}{l}\text { João Stenghel } \\
\text { Morgante }\end{array}$ & 1969 \\
\hline & & & Maria Pereira de Castro & 1969 & & \\
\hline & Crodowaldo Pavan & 1944 & André Luiz Paranhos Perondin & 1968 & & \\
\hline & & & Antônio Netto Cestari & 1966 & & \\
\hline & & & Elisa Pereira Knapp & 1953 & & \\
\hline & & & Francisco Mauro Salzano & 1955 & & \\
\hline & & & $\begin{array}{l}\text { Hermione Elly Melara de } \\
\text { Campos Bicudo }\end{array}$ & 1967 & & \\
\hline & & & Luiz Edmundo Magalhães & 1958 & & \\
\hline & & & Pedro Henrique Saldanha & 1959 & & \\
\hline & & & Renato Basile & & & \\
\hline & & & Silvio de Almeida Toledo Filho & 1966 & & \\
\hline & & & Willy Beçak & 1964 & & \\
\hline & & & & & Liu Pin Yi & 1967 \\
\hline & Rosina Barros & 1943 & & & & \\
\hline
\end{tabular}


Enquanto as cadeiras básicas de ciências biológicas foram criadas em 1934, a cadeira de biologia geral só teve professor próprio em 1937, tendo André Dreyfus como catedrático. Foi Dreyfus que orientou as primeiras teses em genética, dando início a uma linha de pesquisa que ganhou renome internacional.

Os três primeiros doutoramentos foram defendidos por pesquisadores que ficaram na USP: Rosina de Barros, doutorado em 1943; Crodowaldo Pavan, doutorado em 1944; e Antonio Brito da Cunha, doutorado em 1945. Pavan começou a orientar em 1953 e Cunha, em 1968. Ambos formaram geneticistas que atuaram na USP, Instituto Butantan, Instituto Biológico e em outras universidades brasileiras.

Este grupo recebeu o renomado geneticista Theodosius Dobzhansky, professor da Universidade de Columbia, Estados Unidos, pela primeira vez em 1943 e que retornou em 1949, e de 1955 a 1956. Nestes anos, a cadeira de Biologia contou com o financiamento da Fundação Rockefeller e atraiu pesquisadores de vários países. A partir da cooperação com Dobzhansky, teve início na USP uma linha de pesquisa em genética das drosófilas.

\section{FISIOLOGIA}

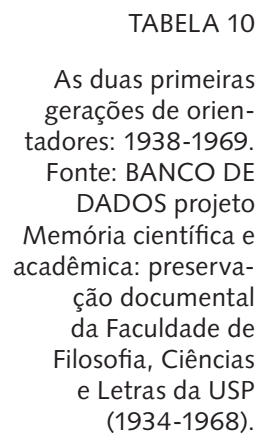

\begin{tabular}{|c|c|c|c|c|c|c|c|c|}
\hline \multirow{2}{*}{$\begin{array}{c}\text { Primeiros } \\
\text { docentes } \\
\text { orientadores }\end{array}$} & \multicolumn{4}{|c|}{$1^{\text {a }}$ geração de orientandos } & \multicolumn{4}{|c|}{$2^{\mathrm{a}}$ geração de orientandos } \\
\hline & Doutores & Data & Mestres & Data & Doutores & Data & Mestres & Data \\
\hline \multirow[t]{7}{*}{$\begin{array}{c}\text { Paulo } \\
\text { Sawaya* }\end{array}$} & $\begin{array}{c}\text { Adolfo Brunner } \\
\text { Júnior }\end{array}$ & 1968 & & & & & & \\
\hline & $\begin{array}{c}\text { Ana Amélia } \\
\text { Ancona Lopez }\end{array}$ & 1957 & & & & & & \\
\hline & $\begin{array}{l}\text { Ary Domingos } \\
\text { do Amaral }\end{array}$ & 1967 & & & & & & \\
\hline & $\begin{array}{c}\text { Benedito } \\
\text { Oliveira Filho }\end{array}$ & 1964 & & & & & & \\
\hline & $\begin{array}{c}\text { Celso Paulo } \\
\text { Jaeger }\end{array}$ & 1960 & & & & & & \\
\hline & $\begin{array}{l}\text { Domingos } \\
\text { Valente }\end{array}$ & 1948 & & & & & & \\
\hline & $\begin{array}{c}\text { Erasmo Garcia } \\
\text { Mandes }\end{array}$ & 1944 & & & & & $\begin{array}{l}\text { Marilda } \\
\text { Inês } \\
\text { Sawaya } \\
\text { Altimari }\end{array}$ & 1968 \\
\hline
\end{tabular}




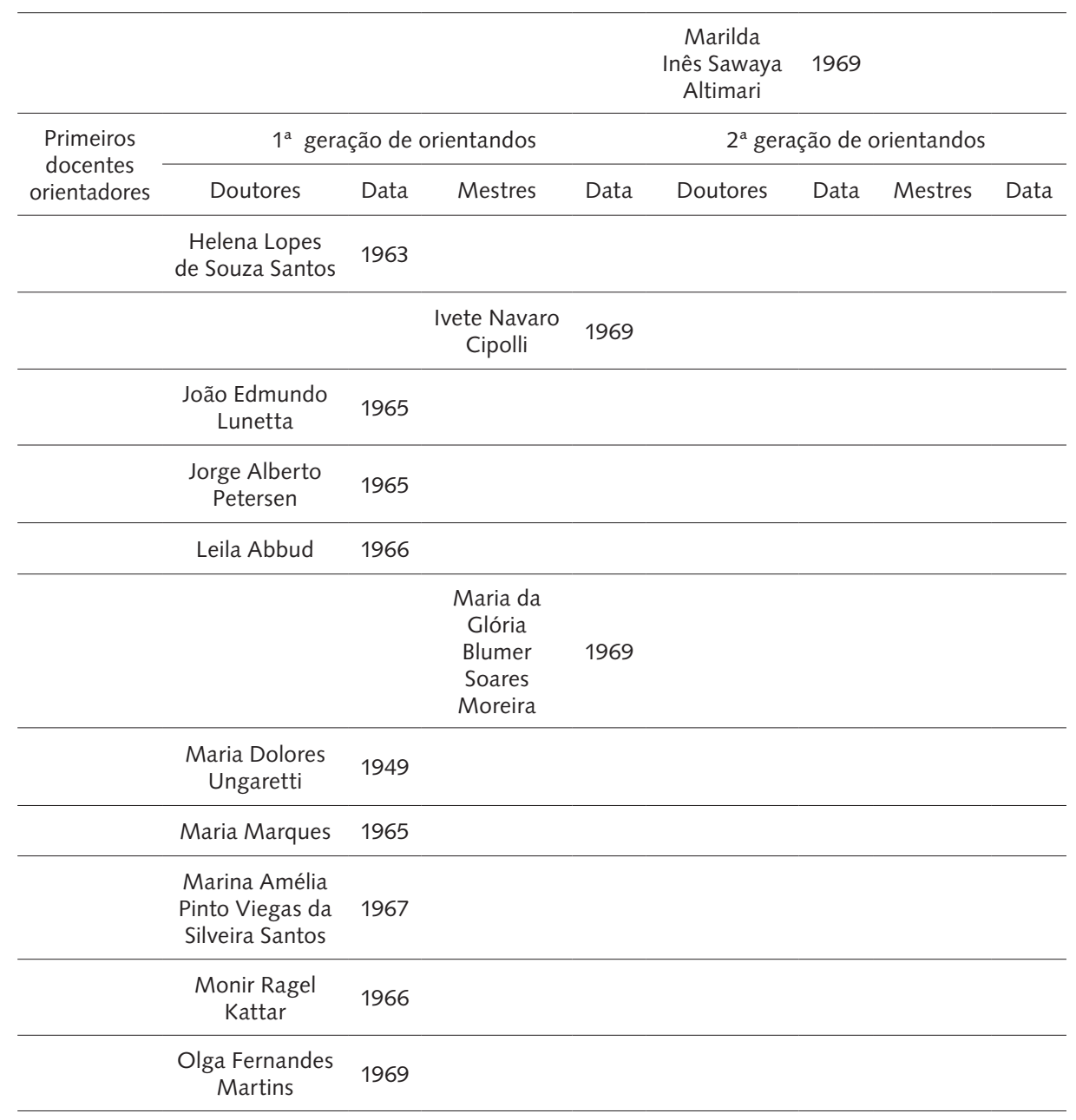

Linha iniciada por Paulo Sawaya, catedrático em 1939, que orientou muitos doutoramentos, tanto no período de 1944 a 1969 quanto nos anos posteriores à reforma universitária. Trabalhou em fisiologia vegetal e animal. Seu primeiro aluno foi Erasmo Garcia Mendes, que ficou na USP e começou a orientar no final dos anos 1960.

\section{GEOLOGIA}

Esta área fez parte da subseção de ciências naturais até 1957, quando lei federal tornou os cursos de geologia independentes. Foi uma área muito ativa e com muitos doutoramentos defendidos. O primeiro orientador foi 
Reynaldo Ramos Saldanha da Gama e teve como aluno Rui Ribeiro Franco, que fez carreira na USP. Franco orientou a tese de William Gerson Rolim de Camargo, que também permaneceu na USP.

O catedrático que mais orientou doutoramentos em geologia foi Viktor Leinz, que atuou de 1948 a 1969. Entre seus orientandos, Setembrino Petri ficou na USP e passou a orientar nos anos 1960; Geraldo Conrado Melcher passou a orientar teses no final dos anos 1960. Outro catedrático da área, também bastante conhecido, foi Josué Camargo Mendes, livre-docente em 1950, que orientou pesquisas mais voltadas para a paleontologia, de 1964 a 1971.

A área de geologia tinha assim um grande número de orientadores envolvidos. Merece destaque, também, o fato de que a maior parte das pesquisas realizadas nesta linha foi sobre minerais encontráveis nas várias regiões brasileiras.

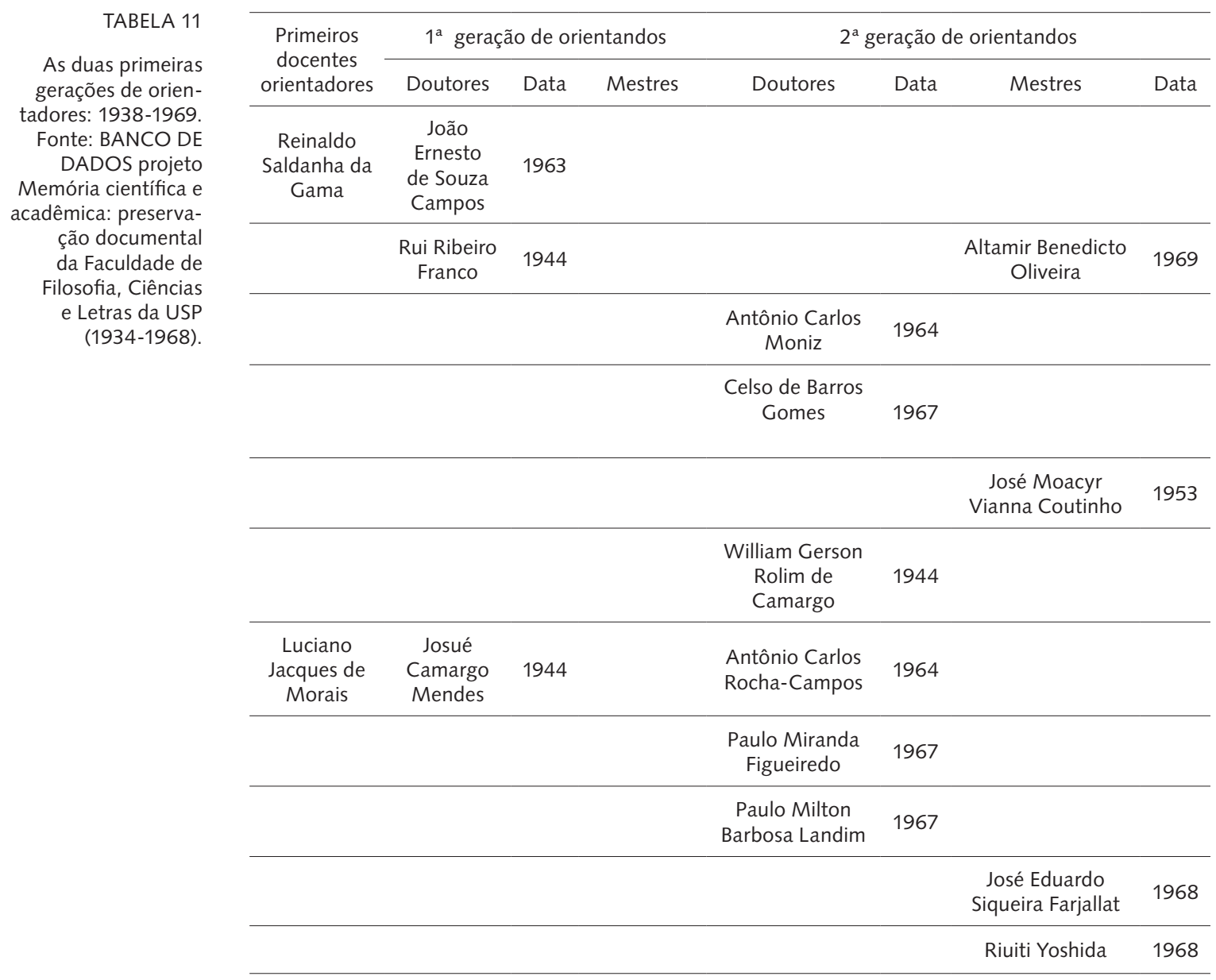




\begin{tabular}{|c|c|c|c|c|c|c|c|}
\hline \multirow{2}{*}{$\begin{array}{c}\text { Primeiros } \\
\text { docentes } \\
\text { orientadores }\end{array}$} & \multicolumn{3}{|c|}{$1^{\mathrm{a}}$ geração de orientandos } & \multicolumn{4}{|c|}{$2^{\mathrm{a}}$ geração de orientandos } \\
\hline & Doutores & Data & Mestres & Doutores & Data & Mestres & Data \\
\hline & & & & & & $\begin{array}{c}\text { Mary Elizabeth } \\
\text { Cerruti Bernardes } \\
\text { Oliveira }\end{array}$ & 1969 \\
\hline & & & & & & $\begin{array}{c}\text { Ronaldo Gama de } \\
\text { Carvalho }\end{array}$ & 1969 \\
\hline \multirow[t]{20}{*}{ Viktor Leinz } & $\begin{array}{l}\text { Setembrino } \\
\text { Petri }\end{array}$ & 1948 & & $\begin{array}{l}\text { Vicente José } \\
\text { Fulfaro }\end{array}$ & 1967 & & \\
\hline & & & & Kenitiro Suguio & 1968 & & \\
\hline & $\begin{array}{c}\text { Sérgio } \\
\text { Estanislau } \\
\text { do Amaral }\end{array}$ & 1954 & & & & & \\
\hline & $\begin{array}{l}\text { Rheinholt } \\
\text { Ellert }\end{array}$ & 1958 & & & & & \\
\hline & $\begin{array}{l}\text { Alfredo } \\
\text { José Simon } \\
\text { Bjornberg }\end{array}$ & 1958 & & & & & \\
\hline & Henry Mau & 1960 & & & & & \\
\hline & $\begin{array}{l}\text { Geraldo } \\
\text { Conrado } \\
\text { Melcher }\end{array}$ & 1961 & & $\begin{array}{c}\text { Eduardo } \\
\text { Camilher } \\
\text { Damasceno }\end{array}$ & 1967 & & \\
\hline & & & & & & Helmut Born & 1969 \\
\hline & $\begin{array}{c}\text { Patrick } \\
\text { J.V.Delaney }\end{array}$ & 1962 & & & & & \\
\hline & $\begin{array}{l}\text { Evaristo } \\
\text { Ribeiro } \\
\text { Filho }\end{array}$ & 1963 & & & & & \\
\hline & $\begin{array}{l}\text { Faustino } \\
\text { Penalva }\end{array}$ & 1963 & & & & & \\
\hline & $\begin{array}{l}\text { André } \\
\text { Davino }\end{array}$ & 1965 & & & & & \\
\hline & $\begin{array}{l}\text { Nelson } \\
\text { Ellert }\end{array}$ & 1966 & & & & & \\
\hline & $\begin{array}{c}\text { Adolfo José } \\
\text { Melfi }\end{array}$ & 1967 & & & & & \\
\hline & $\begin{array}{l}\text { Aladir } \\
\text { Paganelli } \\
\text { Barbour }\end{array}$ & 1968 & & & & & \\
\hline & & & $\begin{array}{l}\text { Márcia } \\
\text { Szikszay }\end{array}$ & 1969 & & & \\
\hline & & & $\begin{array}{l}\text { Carlos } \\
\text { Augusto } \\
\text { Luciano } \\
\text { Isotta }\end{array}$ & 1969 & & & \\
\hline & & & $\begin{array}{c}\text { Kojy } \\
\text { Kawashita }\end{array}$ & 1969 & & & \\
\hline & & & $\begin{array}{l}\text { Bruno } \\
\text { Minioli }\end{array}$ & 1969 & & & \\
\hline & & & $\begin{array}{l}\text { Andrea } \\
\text { Bartorelli }\end{array}$ & 1969 & & & \\
\hline
\end{tabular}




\section{SUBSEÇÃO DE HISTÓRIA E GEOGRAFIA}

Apesar de formarem a mesma subseção e terem uma graduação unificada até 1956, as áreas da história e da geografia tiveram cátedras e linhas de pesquisa distintas.

Os doutoramentos em história tiveram início com a atuação de Jean Gagé, que orientou quatro teses de 1942 a 1944. Três de seus alunos fizeram carreira na USP: Eurípedes Simões de Paula; Alice Cannabrava,e Astrogildo Rodrigues de Mello. Gagé orientou também a tese de Olga Pantaleão, defendida em 1944.

Eurípedes Simões de Paula formou gerações de historiadores da USP, entre eles Eduardo d'Oliveira França, Pedro Moacyr Campos e, nos anos 1950, Roque Spencer M. de Barros, que atuaria depois na área de educação na USP. Eurípedes continuou orientando até os anos 1970.

Alice Cannabrava atuou depois na área da história econômica e, em 1964 passou a ser professora da nova Faculdade de Ciências Econômicas e Administração da USP, atual FEA, da qual foi catedrática e diretora. Eduardo d' Oliveira França foi outro professor da área que formou gerações de historiadores, dentre os quais vários ficaram na USP, como Manuel Nunes Dias, doutor em 1957; Carlos Guilherme Mota, mestre em 1967; e Fernando Novais, doutor no início dos anos 1970.

No final dos anos 1950, Sérgio Buarque de Holanda, historiador já bastante conhecido, foi contratado pela USP e se tornou catedrático em 1958. Começou a orientar teses nos anos 1960 e formou uma geração de pesquisadores que depois fizeram carreira na USP. Entre seus alunos podemos citar Maria Odila Dias, Maria Tereza Schorer Petrone, Suely Robles de Queiroz, José Sebastião Witter e Boris Fausto. Em geral orientou pesquisas em história do Brasil.

Nestes anos, foram se constituindo assim, na área da história, diferentes linhas de pesquisa: história antiga, medieval, moderna, Brasil, América e Ibérica.

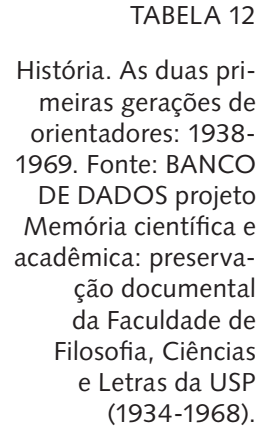

\begin{tabular}{|c|c|c|c|c|c|c|c|c|}
\hline \multirow{2}{*}{$\begin{array}{c}\text { Primeiros } \\
\text { docentes } \\
\text { orientadores }\end{array}$} & \multicolumn{4}{|c|}{$1^{\mathrm{a}}$ geração de orientandos } & \multicolumn{4}{|c|}{$2^{a}$ geração de orientandos } \\
\hline & Doutores & Data & Mestres & Data & Doutores & Data & Mestres & Data \\
\hline \multirow[t]{3}{*}{ Jean Gagé } & $\begin{array}{l}\text { Alice Piffer } \\
\text { Canabrava }\end{array}$ & 1942 & & & & & & \\
\hline & \multicolumn{3}{|c|}{ Eurípedes Simões de Paula } & 1942 & $\begin{array}{l}\text { Eduardo d'Oli- } \\
\text { veira França }\end{array}$ & 1945 & & \\
\hline & & & & & $\begin{array}{c}\text { Pedro Moacyr } \\
\text { Campos }\end{array}$ & 1945 & & \\
\hline
\end{tabular}




\begin{tabular}{|c|c|c|c|c|c|c|c|c|}
\hline \multirow{2}{*}{$\begin{array}{c}\text { Primeiros } \\
\text { docentes } \\
\text { orientadores }\end{array}$} & \multicolumn{4}{|c|}{$1^{\mathrm{a}}$ geração de orientandos } & \multicolumn{4}{|c|}{$2^{\mathrm{a}}$ geração de orientandos } \\
\hline & Doutores & Data & Mestres & Data & Doutores & Data & Mestres & Data \\
\hline & & & & & $\begin{array}{c}\text { Roque Spencer } \\
\text { Maciel de } \\
\text { Barros }\end{array}$ & 1955 & & \\
\hline & & & & & $\begin{array}{l}\text { Pe. José Maria } \\
\text { Corrêa S.J. }\end{array}$ & 1966 & & \\
\hline & & & & & Aldo Janotti & 1966 & & \\
\hline & & & & & $\begin{array}{l}\text { Salvatore } \\
\text { D'Onofrio }\end{array}$ & 1968 & & \\
\hline & & & & & Jaime Pinski & 1968 & & \\
\hline & & & & & $\begin{array}{c}\text { Maria da Glória } \\
\text { Alves Portal }\end{array}$ & 1969 & & \\
\hline & & & & & $\begin{array}{l}\text { Marcos } \\
\text { Margulies }\end{array}$ & 1969 & & \\
\hline & & & & & & & $\begin{array}{l}\text { Nachman } \\
\text { Falbel }\end{array}$ & 1969 \\
\hline & & & & & & & $\begin{array}{l}\text { José } \\
\text { Roberto } \\
\text { Almeida } \\
\text { Filho }\end{array}$ & 1969 \\
\hline & $\begin{array}{l}\text { Astrogildo } \\
\text { Rodrigues } \\
\text { de Melo }\end{array}$ & 1942 & & & Myriam Ellis & 1955 & & \\
\hline & $\begin{array}{c}\text { Olga } \\
\text { Pantaleão }\end{array}$ & 1944 & & & & & & \\
\hline $\begin{array}{l}\text { Fernand } \\
\text { Braudel }\end{array}$ & $\begin{array}{l}\text { Luiz Lizanti } \\
\text { Filho }\end{array}$ & 1962 & & & & & & \\
\hline \multirow[t]{7}{*}{$\begin{array}{c}\text { Sérgio } \\
\text { Buarque de } \\
\text { Holanda }\end{array}$} & $\begin{array}{l}\text { Frank Perry } \\
\text { Goldman }\end{array}$ & 1961 & & & & & & \\
\hline & $\begin{array}{c}\text { José Ferreira } \\
\text { Carrato }\end{array}$ & 1961 & & & & & & \\
\hline & $\begin{array}{l}\text { Maria } \\
\text { Thereza } \\
\text { Schorer } \\
\text { Petrone }\end{array}$ & 1964 & & & & & & \\
\hline & & & $\begin{array}{c}\text { Maria } \\
\text { Odila Dias } \\
\text { Curly }\end{array}$ & 1965 & & & & \\
\hline & & & $\begin{array}{c}\text { Suely } \\
\text { Robles de } \\
\text { Queiroz }\end{array}$ & 1966 & & & & \\
\hline & $\begin{array}{l}\text { Herbert } \\
\text { Cahn }\end{array}$ & 1967 & & & & & & \\
\hline & $\begin{array}{l}\text { José } \\
\text { Gonçalves } \\
\text { Salvador }\end{array}$ & 1967 & & & & & & \\
\hline
\end{tabular}




\begin{tabular}{|c|c|c|c|c|c|c|c|c|}
\hline \multirow{2}{*}{$\begin{array}{l}\text { Primeiros } \\
\text { docentes } \\
\text { orientadores }\end{array}$} & \multicolumn{4}{|c|}{$1^{\mathrm{a}}$ geração de orientandos } & \multicolumn{4}{|c|}{$2^{\mathrm{a}}$ geração de orientandos } \\
\hline & Doutores & Data & Mestres & Data & Doutores & Data & Mestres & Data \\
\hline & $\begin{array}{l}\text { Jeanne } \\
\text { Barrance de } \\
\text { Castro }\end{array}$ & 1968 & & & & & & \\
\hline & $\begin{array}{l}\text { Júlia Maria } \\
\text { Leonor } \\
\text { Scarano }\end{array}$ & 1969 & & & & & & \\
\hline & & & $\begin{array}{c}\text { José } \\
\text { Sebastião } \\
\text { Witter }\end{array}$ & 1969 & & & & \\
\hline & Boris Fausto & 1969 & & & & & & \\
\hline
\end{tabular}

\section{GEOGRAFIA}

TABELA 13

As duas primeiras gerações de orientadores: 1938-1969.

Fonte: BANCO DE

DADOS projeto

Memória científica e acadêmica: preserva-

ção documental

da Faculdade de

Filosofia, Ciências

e Letras da USP (1934-1968)

\begin{tabular}{|c|c|c|c|c|c|c|c|c|}
\hline \multirow{2}{*}{$\begin{array}{c}\text { Primeiros } \\
\text { docentes } \\
\text { orientadores }\end{array}$} & \multicolumn{3}{|c|}{$1^{\mathrm{a}}$ geração de orientandos } & \multicolumn{5}{|c|}{$2^{a}$ geração de orientandos } \\
\hline & Doutores & Data & Mestres & Data & Doutores & Data & Mestres & Data \\
\hline \multirow{7}{*}{$\begin{array}{c}\text { Pierre } \\
\text { Monbeig }\end{array}$} & Ary França & 1945 & & & & & & \\
\hline & $\begin{array}{l}\text { João Dias } \\
\text { da Silveira }\end{array}$ & 1946 & & & $\begin{array}{c}\text { Carlos Augusto } \\
\text { de Figueiredo } \\
\text { Monteiro }\end{array}$ & 1967 & & \\
\hline & & & & & $\begin{array}{c}\text { Elina de Oliveira } \\
\text { Santos }\end{array}$ & 1950 & & \\
\hline & & & & & Pasquale Petrone & 1960 & & \\
\hline & $\begin{array}{l}\text { Maria } \\
\text { Conceição } \\
\text { Vicente de } \\
\text { Carvalho }\end{array}$ & 1944 & & & & & & \\
\hline & $\begin{array}{c}\text { Nice Lecocq } \\
\text { Müller }\end{array}$ & 1945 & & & & & $\begin{array}{c}\text { Liliana Laganá } \\
\text { Fernandes }\end{array}$ & 1969 \\
\hline & $\begin{array}{c}\text { Renato } \\
\text { da Silveira } \\
\text { Mendes }\end{array}$ & 1948 & & & & & & \\
\hline \multirow[t]{4}{*}{$\begin{array}{c}\text { Aroldo E. } \\
\text { de Azevedo }\end{array}$} & $\begin{array}{c}\text { José Ribeiro } \\
\text { de Araujo } \\
\text { Filho }\end{array}$ & 1950 & & & & & & \\
\hline & $\begin{array}{l}\text { Aziz Nacib } \\
\text { Ab'Saber }\end{array}$ & 1957 & & & & & & \\
\hline & $\begin{array}{l}\text { Antonio } \\
\text { Rocha } \\
\text { Penteado }\end{array}$ & 1963 & & & & & & \\
\hline & & & $\begin{array}{l}\text { Uyvão } \\
\text { Pegaia }\end{array}$ & 1965 & & & & \\
\hline
\end{tabular}


O primeiro professor da subseção de geografia foi Pierre Deffontaines, responsável pelas áreas da geografia humana e física. Em 1935 foi contratado Pierre Monbeig, que orientou as primeiras teses na área, de 1944 a 1948. Entre seus alunos ficaram na USP: Ary França; João Dias da Silveira, que começou a orientar teses nos anos 1960, tendo entre seus alunos Pasquale Petrone, que fez carreira na USP, e Carlos Augusto de Figueiredo Monteiro. Monbeig também orientou Nice Leloch Muller, que também orientou teses nos anos 1960.

Outra linha de pesquisa em geografia foi iniciada por Aroldo de Azevedo. Doutor em 1942, este professor orientou teses a partir de 1950. Foram seus alunos e permaneceram na USP: José Ribeiro de Araujo Filho, Aziz N. Ab’ Saber e Antonio Rocha Penteado.

\section{SUBSEÇÃO DE CIÊNCIAS SOCIAIS E POLÍTICAS}

Participaram desta subseção especialistas em diferentes áreas: sociologia e ciências políticas, etnologia, antropologia, estatística e economia política.

Duas cadeiras eram dedicadas à sociologia. Foram regentes da cadeira de sociologia 1: Paul Arbousse-Bastide (1934), Claude Levy-Strauss (1935-1937), Roger Bastide (1938-1953) e Florestan Fernandes (1953-1969). Na cadeira de sociologia 2: Paul Arbousse-Bastide (1934-1940), Roger Bastide (1941-1942), Fernando de Azevedo (1942-1964) e Ruy Coelho (1964-1964).

Paul Arbousse-Bastide orientou a tese de Lourival Gomes Machado, que tornou-se professor da USP e que orientou a tese de Paula Beiguelman defendida em 1961, que também ganhou destaque na USP. Roger Bastide desempenhou importante papel na formação de novos pesquisadores, contribuindo inclusive para a implantação de novas áreas de pesquisa. Foram seus alunos: Lucila Hermann, doutora em 1945, depois professora na Faculdade de Economia e Administração; Gilda de Mello e Souza, doutora em 1950, que fez carreira na USP na área da Estética.Com Jean Maugué, Bastide coorientou Annita C. M. Cabral, doutora em 1945, que fez carreira na área da psicologia.

Fernando de Azevedo, educador reconhecido e um dos fundadores da USP, orientou Florestan Fernandes, doutor em 1950, e Antonio Cândido de Mello Souza, doutor em 1954, que se tornaram professores da USP e ganharam destaque em suas áreas de atuação. Florestan Fernandes 
formou uma escola tendo sido orientador de pesquisadores que ganharam renome: Fernando Henrique Cardoso, mestre em 1953, doutor em 1961; Otávio Ianni, mestre em 1957, doutor em 1961. Também orientou as teses de Maria Sylvia de Carvalho Franco Moreira, Marialice M. Foracchi, Luiz Pereira, Rubens Brandão Lopes, Gabriel Cohn, Paul Israel Singer, José de Souza Martins, entre outros. Antonio Cândido já atuava na USP desde os anos 1940, tendo feito livre-docência em literatura brasileira em 1945, mas seu doutorado foi em sociologia (1954). Nos anos seguintes passou a trabalhar com teoria literária e literatura comparada, área na qual começou a orientar nos anos 1960.

Desde o início da FFCL, a área de etnologia e língua tupi teve como regente Plinio Marques da Silva Ayrosa, que teve um orientando, Carlos Drumond, que fez carreira na USP.

Nos anos 1940, Emilio Willems atuou na área da antropologia da FFCL, orientador de Egon Schaden, que fez carreira na USP e formou alguns dos primeiros antropólogos paulistas, como Eunice R. Durham (mestre em 1964 e doutora em 1966), João Baptista Borges Pereira (doutor em 1966) e Thekla Hartmann (doutora em 1966).

Outra cadeira desta subseção foi a de estatística. O catedrático era Milton da Silva Rodrigues, que orientou teses de 1942 a 1950. Entre seus alunos, Eduardo Alcântara de Oliveira (doutor em 1942) e Lindo Fava (doutor em 1948) permaneceram na USP.

Também constava nesta subseção a cadeira de economia política, finanças e história das doutrinas econômicas. De 1935 a 1938, teve como professores Edgard O.Gotsch, François Perroux, René Courtin e Pierre Fromont. Em 1939 foi contratado Paul Hugon, que orientou teses na FFCL de 1945 até a reforma universitária de 1969. Entre seus alunos, destaque para José Francisco de Camargo, Dorival Teixeira Vieira, Nuno Fidelino de Figueiredo e Diva Benevides Pinto. Em 1969, Hugon e seus assistentes se transferiram para a FEA-USP.

Por fim, é bom sublinhar que, como nesta análise estão sendo consideradas somente as teses defendidas na FFCL-USP, alguns nomes da escola de sociologia paulista, como Maria Isaura Pereira de Queiroz (formada no exterior) e Gioconda Mussolini, não têm, em nossas tabelas, o destaque que merecem. 
TABELA 14

As duas primeiras gerações de orientadores: 1938-1969.

Fonte: BANCO DE

DADOS projeto

Memória científica e acadêmica: preserva-

ção documental

da Faculdade de

Filosofia, Ciências

e Letras da USP

(1934-1968)

\begin{tabular}{|c|c|c|c|c|c|c|}
\hline \multirow{2}{*}{$\begin{array}{c}\text { Primeiros } \\
\text { docentes } \\
\text { orientadores }\end{array}$} & \multicolumn{2}{|c|}{$\begin{array}{c}1^{\mathrm{a}} \text { geração de } \\
\text { orientandos }\end{array}$} & \multicolumn{4}{|c|}{$2^{a}$ geração de orientandos } \\
\hline & Doutores & Data & Doutores & Data & Mestres & Data \\
\hline $\begin{array}{l}\text { Paul Arbousse } \\
\text { Bastide }\end{array}$ & $\begin{array}{l}\text { Lourival } \\
\text { Gomes } \\
\text { Machado }\end{array}$ & 1942 & Paula Beiguelmann & 1961 & & \\
\hline \multirow[t]{2}{*}{ Roger Bastide } & $\begin{array}{l}\text { Lucila } \\
\text { Hermann }\end{array}$ & 1945 & & & & \\
\hline & $\begin{array}{c}\text { Gilda Rocha } \\
\text { de Mello e } \\
\text { Souza }\end{array}$ & 1950 & & & & \\
\hline \multirow[t]{17}{*}{$\begin{array}{l}\text { Fernando de } \\
\text { Azevedo }\end{array}$} & $\begin{array}{l}\text { Florestan } \\
\text { Fernandes }\end{array}$ & 1950 & $\begin{array}{c}\text { Fernando Henrique } \\
\text { Cardoso }\end{array}$ & 1961 & $\begin{array}{c}\text { Fernando Henrique } \\
\text { Cardoso }\end{array}$ & 1953 \\
\hline & & & Otavio Ianni & 1961 & Otávio lanni & 1957 \\
\hline & & & Luiz Pereira & 1961 & & \\
\hline & & & $\begin{array}{c}\text { Maria Sylvia de } \\
\text { Carvalho Franco } \\
\text { Moreira }\end{array}$ & 1964 & & \\
\hline & & & $\begin{array}{l}\text { Marialice Mancarini } \\
\text { Foracchi }\end{array}$ & 1964 & & \\
\hline & & & $\begin{array}{l}\text { Juarez Rubens } \\
\text { Brandão Lopes }\end{array}$ & 1964 & José Carlos Pereira & 1964 \\
\hline & & & Paul Israel Singer & 1966 & Celso de Rui Beisiegel & 1964 \\
\hline & & & $\begin{array}{c}\text { Roberto Cardoso de } \\
\text { Oliveira }\end{array}$ & 1966 & $\begin{array}{c}\text { Claudio José Torres } \\
\text { Vouga }\end{array}$ & 1964 \\
\hline & & & $\begin{array}{l}\text { Leôncio Martins } \\
\text { Rodrigues Netto }\end{array}$ & 1967 & Lourde Solla & 1964 \\
\hline & & & & & Gabriel Bolaffi & 1965 \\
\hline & & & & & José de Souza Martins & 1966 \\
\hline & & & & & $\begin{array}{c}\text { José Cesar Aprilanti } \\
\text { Gnaccarini }\end{array}$ & 1966 \\
\hline & & & & & Gabriel Cohn & 1967 \\
\hline & $\begin{array}{l}\text { Antonio } \\
\text { Cândido } \\
\text { de Mello e } \\
\text { Souza }\end{array}$ & 1954 & & & $\begin{array}{l}\text { Therezinha Aparecida } \\
\text { Porto Ancona }\end{array}$ & 1967 \\
\hline & & & & & Maria Helena Gumbecki & 1967 \\
\hline & & & & & $\begin{array}{c}\text { Roberto de Oliveira } \\
\text { Brandão }\end{array}$ & 1969 \\
\hline & & & & & Suzi Frankl Sperber & 1969 \\
\hline \multirow[t]{2}{*}{$\begin{array}{l}\text { Emilio } \\
\text { Willems }\end{array}$} & $\begin{array}{l}\text { Egon } \\
\text { Schaden }\end{array}$ & 1945 & & & Eunice Ribeiro Durham & 1964 \\
\hline & & & $\begin{array}{l}\text { Eunice Ribeiro } \\
\text { Durham }\end{array}$ & 1966 & & \\
\hline
\end{tabular}




\begin{tabular}{|c|c|c|c|c|c|c|}
\hline \multirow{2}{*}{$\begin{array}{c}\text { Primeiros } \\
\text { docentes } \\
\text { orientadores }\end{array}$} & \multicolumn{2}{|c|}{$\begin{array}{c}1^{\mathrm{a}} \text { geração de } \\
\text { orientandos }\end{array}$} & \multicolumn{4}{|c|}{$2^{a}$ geração de orientandos } \\
\hline & Doutores & Data & Doutores & Data & Mestres & Data \\
\hline & & & $\begin{array}{c}\text { João Baptista Borges } \\
\text { Pereira }\end{array}$ & 1966 & & \\
\hline & & & $\begin{array}{l}\text { Thekla Olga } \\
\text { Hartmann }\end{array}$ & 1966 & & \\
\hline & $\begin{array}{l}\text { Lavinia Costa } \\
\text { Villela }\end{array}$ & 1945 & & & & \\
\hline $\begin{array}{c}\text { Plinio } \\
\text { Marques da } \\
\text { Silva Ayrosa }\end{array}$ & & & Carlos Drumond & 1946 & & \\
\hline \multirow[t]{2}{*}{$\begin{array}{c}\text { Milton } \\
\text { Rodriguesf }\end{array}$} & $\begin{array}{c}\text { Eduardo } \\
\text { Alcântara de } \\
\text { Oliveira }\end{array}$ & 1942 & & & & \\
\hline & Lindo Fava & 1948 & $\begin{array}{l}\text { José Severo de } \\
\text { Camargo Pereira }\end{array}$ & 1950 & & \\
\hline \multirow[t]{7}{*}{ Paul Hugon } & $\begin{array}{c}\text { Dorival } \\
\text { Teixeira } \\
\text { Vieira }\end{array}$ & 1945 & & & & \\
\hline & $\begin{array}{c}\text { José } \\
\text { Francisco de } \\
\text { Camargo }\end{array}$ & 1950 & & & & \\
\hline & $\begin{array}{l}\text { Hélio } \\
\text { Schlittler } \\
\text { Silva }\end{array}$ & 1951 & & & & \\
\hline & $\begin{array}{l}\text { Nuno } \\
\text { Fidelino de } \\
\text { Figueiredo }\end{array}$ & 1952 & & & & \\
\hline & $\begin{array}{l}\text { Diva } \\
\text { Benevides } \\
\text { Pinto }\end{array}$ & 1962 & & & & \\
\hline & $\begin{array}{l}\text { Henrique } \\
\text { Rattner }\end{array}$ & 1968 & & & & \\
\hline & $\begin{array}{c}\text { Carlos } \\
\text { Marques } \\
\text { Pinho }\end{array}$ & 1969 & & & & \\
\hline
\end{tabular}

\section{SEÇÃO DE LETRAS}

$\mathrm{Na}$ Seção de Letras, os primeiros professores foram Francisco da Silveira Bueno (linguista e filólogo brasileiro, catedrático em 1939), Fidelino de Figueiredo (professor português contratado em 1938 para literatura luso-brasileira) e Urbano Canuto Soares (também português, para língua e 
literatura latina). As primeiras teses defendidas na seção foram em linguas clássicas, português e literatura portuguesa.

Francisco S. Bueno orientou algumas teses de 1944 a 1964 e Fidelino de Figueiredo orientou de 1948 a 1965 e, entre seus alunos, o destaque fica para Antonio A. Soares Amora e Sigismundo Spina (1950), que fizeram carreira na USP. Amora orientou, entre outros, Massaud Moisés (1954).

Urbano Canuto Soares orientou de 1944 a 1954. Em 1944, foi defendida a tese de Theodoro H.Maurer Jr., que atuou em linguística românica e orientou Isaac Nicolau Salum e Antonio Tonioli, que fizeram carreira na USP e posteriormente se tornaram orientadores.

Em línguas estrangeiras, as teses apareceram mais tarde, nos anos 1950. Alfred Bonzon aparece orientando em língua francesa Marlyse Meyer, com tese de 1957 e Vitor de Almeida Ramos, que fez carreira na USP; Ítalo B. Betarello em língua italiana orientou, entre outros, Alfredo Bosi, que fez carreira na USP; em língua alemã, Pedro de Almeida Moura que orientou, entre outros, Erwin T. Rosenthal, que fez longa carreira na USP. Aparecem também, como orientadores, Mario Pereira de Souza que orientou, em língua brasileira, José Aderaldo Castello; e, em hebraico, Fritz Pincuss.

\begin{tabular}{|c|c|c|c|c|c|}
\hline $\begin{array}{l}\text { As duas primeiras } \\
\text { geracões de orien- }\end{array}$ & $\begin{array}{l}\text { Primeiros docentes } \\
\text { orientadores }\end{array}$ & Doutores & Data & Doutores & Data \\
\hline $\begin{array}{l}\text { Fonte: BANCO DE } \\
\text { DADOS projeto }\end{array}$ & Francisco da Silveira Bueno & $\begin{array}{c}\text { Maria de Lourdes de Paula } \\
\text { Martins }\end{array}$ & 1944 & & \\
\hline $\begin{array}{l}\text { ção documental } \\
\text { da Faculdade de }\end{array}$ & & $\begin{array}{c}\text { Dinorah Silveira Campos } \\
\text { Pecoraro }\end{array}$ & 1951 & & \\
\hline e Letras da USP & & Felipe Jorge & 1964 & & \\
\hline & & $\begin{array}{c}\text { Antonio Augusto Soares } \\
\text { Amora }\end{array}$ & 1946 & Winifred Kera Stevens & 1951 \\
\hline & Fidelino de Figueiredo & & & Massaud Moises & 1954 \\
\hline & & & & Naief Safady & 1959 \\
\hline & & & & $\begin{array}{c}\text { Júlio Gregório Garcia } \\
\text { Morejon }\end{array}$ & 1960 \\
\hline
\end{tabular}




\begin{tabular}{|c|c|c|c|c|}
\hline $\begin{array}{l}\text { Primeiros docentes } \\
\text { orientadores }\end{array}$ & Doutores & Data & Doutores & Data \\
\hline & & & $\begin{array}{l}\text { Fernando Manuel de } \\
\text { Mendonça }\end{array}$ & 1965 \\
\hline & & & $\begin{array}{c}\text { Maria Aparecida de Campos } \\
\text { Brando }\end{array}$ & 1967 \\
\hline & & & Nelly Novaes Coelho & 1967 \\
\hline & & & $\begin{array}{l}\text { Maria Helena Ribeiro da } \\
\text { Cunha }\end{array}$ & 1968 \\
\hline & & & Carlos Felipe Moisés & 1968 \\
\hline & Sigismundo Spina & 1950 & Luiz Piva & 1968 \\
\hline & & & Ariovaldo da Fonseca & 1969 \\
\hline & & & Fernando Marson & 1969 \\
\hline & & & Dino Fioravente Preti & 1969 \\
\hline & $\begin{array}{c}\text { Theodoro Henrique Maurer } \\
\text { Jr. }\end{array}$ & 1944 & & \\
\hline \multirow[t]{5}{*}{ Urbano Canuto Soares } & & & Isaac Nicolau Salum & 1953 \\
\hline & & & Ataliba Teixeira de Castilho & 1966 \\
\hline & Armando Tonioli & 1954 & Enzo del Carratore & 1965 \\
\hline & & & Maria Evangelina Soeiro & 1969 \\
\hline & Marlyse Madaleine Meyer & 1957 & & \\
\hline \multirow[t]{2}{*}{ Alfred Bonzon } & Vitor de Almeida Ramos & 1961 & & \\
\hline & Carla Inama & 1957 & & \\
\hline \multirow[t]{3}{*}{ Italo Bonfim Bettarello } & $\begin{array}{c}\text { Antonio Lázaro de Almeida } \\
\text { Prado }\end{array}$ & 1961 & & \\
\hline & Alfredo Bosi & 1964 & & \\
\hline & Sylvia Barbosa Ferraz & 1950 & & \\
\hline \multirow[t]{4}{*}{ Pedro de Almeida Moura } & Erwin Theodor Rosenthal & 1953 & Ottmar Hertkonn & 1964 \\
\hline & & & Marion Fleischer & 1965 \\
\hline & Delton de Mattos da Silva & 1960 & & \\
\hline & José Aderaldo Castello & 1950 & $\begin{array}{l}\text { Luiz Geraldo Toledo } \\
\text { Machado }\end{array}$ & 1967 \\
\hline Mario Pereira de Souza & Zvi Caspi MA & 1964 & & \\
\hline Fritz Pinkuss & & & & \\
\hline
\end{tabular}




\section{SEÇÃO DE EDUCAÇÃO}

Os cursos do Instituto de Educação (antiga Escola Normal da Praça da República) foram incorporados à USP em 1934. Em 1938 o Instituto foi extinto e seus cursos incorporados à FFCL, com a criação da Seção de Educação, que ficou responsável pela formação pedagógica de nível universitário (cursos complementares para licenciatura, ou seja, para a formação de professores secundários).

Sua primeira catedrática foi Noemy da Silveira Rudolfer, que orientou teses de 1951 a 1953. Entre seus três alunos, destaque para Arrigo Leonardo Angelini, que fez carreira na USP e orientou teses nos anos 1960. Sua área de atuação era a psicologia educacional e, após a Reforma Universitária, foi o primeiro diretor do Instituto de Psicologia da USP.

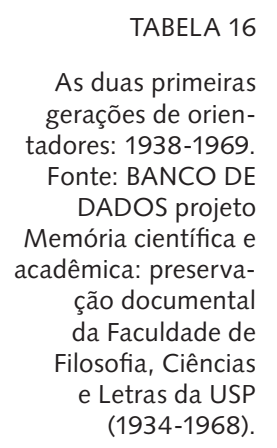

\begin{tabular}{|c|c|c|c|c|}
\hline \multirow{2}{*}{$\begin{array}{c}\text { Primeiros } \\
\text { docentes } \\
\text { orientadores }\end{array}$} & \multicolumn{2}{|l|}{$1^{\text {a }}$ geração de orientandos } & \multicolumn{2}{|l|}{$2^{a}$ geração de orientandos } \\
\hline & Doutores & Data & Doutores & Data \\
\hline \multirow{10}{*}{$\begin{array}{l}\text { Noemy da } \\
\text { Silveira } \\
\text { Rudolfer }\end{array}$} & Maria José de Barros Fornari de Aguirre & 1951 & & \\
\hline & Arrigo Leonardo Angelini & 1953 & Odette Lourenção van Kolck & 1963 \\
\hline & & & Romeu de Morais Almeida & 1965 \\
\hline & & & Luiz Fernando Sfoggia Natalico & 1967 \\
\hline & & & Sofia Caracushomsky & 1968 \\
\hline & & & Samuel Pfromm Netto & 1969 \\
\hline & & & Geraldina Porto Witter & 1969 \\
\hline & & & Nelson Rosamilha & 1969 \\
\hline & & & Carlos Roberto Martins & 1969 \\
\hline & Joel Martins & 1953 & & \\
\hline
\end{tabular}

\section{CONSIDERAÇÕES FINAIS}

Como colocamos, neste primeiro momento de apresentação do projeto Memória científica e acadêmica: preservação documental da Faculdade de Filosofia, Ciências e Letras da USP (1934-1968), nossa intenção foi indicar apenas a formação do que chamamos 'genealogias científicas'. As primeiras 
defesas ocorreram em 1942, perfazendo no período um total de 385 teses de doutoramento e 128 dissertações de mestrado. Além dessas, foi possível verificar a existência de 90 teses de cátedra e 116 teses de Livre-Docência, que não foram contabilizadas no presente gráfico. Verifica-se que houve rápida integração de parte importante daqueles que defendiam doutorados como orientadores de outros mestrados e doutorados em curto período. É neste sentido que as descendências científicas se verificam. Nota-se pelo gráfico de totalizações a seguir que a distribuição de defesas de doutoramento no período tem índice de correlação igual a 0,92, com as totalizações dos mestrados defendidas a partir de 1953.

Estes dados iniciais serão utilizados no decorrer da pesquisa para diferentes temas.

Análise do corpo docente da FFCL e como foi mudando desde o primeiro conjunto de professores, constituído por grande número de estrangeiros convidados.

Análise das transformações por que passaram as seções da FFCL, procurando caracterizar os desdobramentos temáticos.

FIGURA 01 60

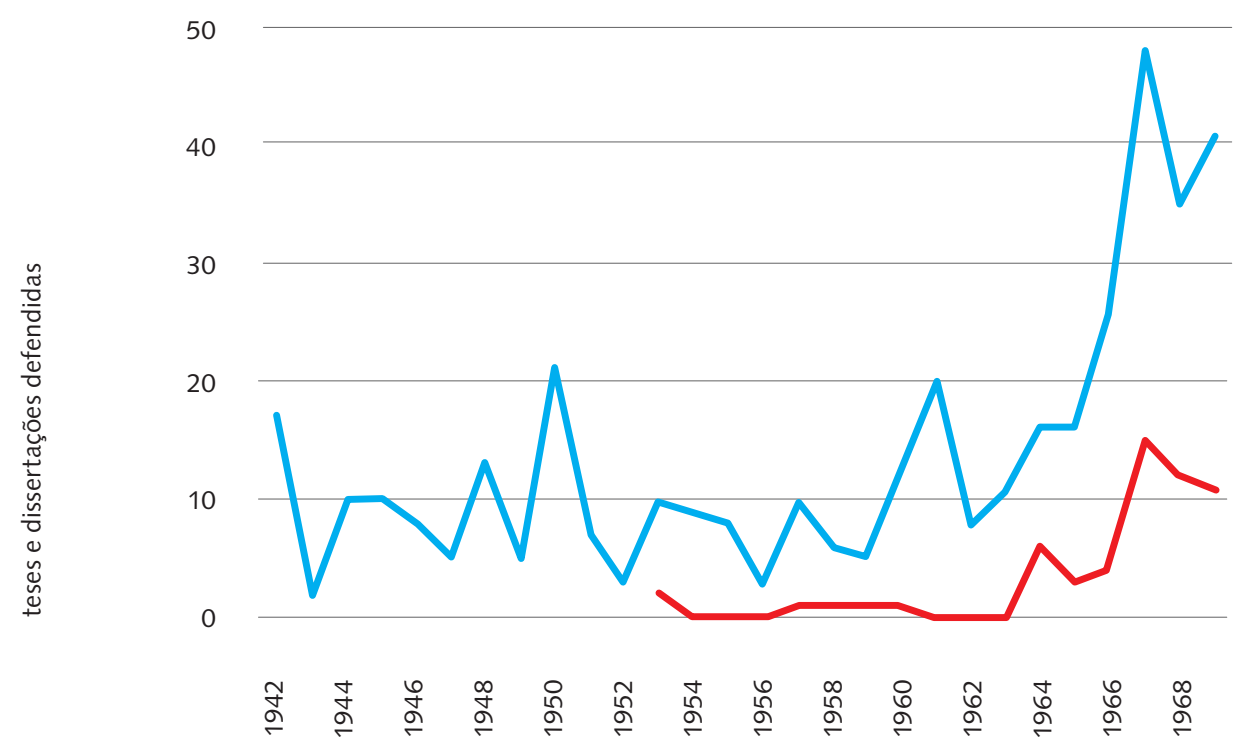


Descrição mais detalhada de conteúdos, autores, áreas, períodos e temas específicos deste conjunto documental, que possibilitará a comparação e análise da produção intelectual da primeira geração de pesquisadores, professores e alunos da USP. Em conjunto com a produção historiográfica existente, o objetivo é também apontar para um quadro mais geral da história da Universidade, tanto quanto especificamente para as pesquisas empreendidas, tendo em vista compreender como foram sendo construídos estilos e tradições de ensino e pesquisa presentes no conjunto da produção inicial da USP.

Análise sobre como foram constituídas as condições para desenvolvimento de atividades de pesquisa na FFCL. Um dos temas que será possível focalizar é o da vinculação do corpo discente ao quadro mais amplo de oferecimento de bolsas de estudos. Assim, para o caso da Física, temos informações que indicam que esta prática já era comum nos anos 1930. No entanto, para as outras seções só encontramos indicativos a partir dos anos 1960.

\section{REFERÊNCIAS BIBLIOGRÁFICAS}

FACULDADE DE FILOSOFIA, CIÊNCIAS E LETRAS DA UNIVERSIDADE DE SÃO PAULO. Anuários da Faculdade de Filosofia, Ciências e Letras. v. 1934-1935. São Paulo: Universidade de São Paulo,.1936.

FACULDADE DE FILOSOFIA, CIÊNCIAS E LETRAS DA UNIVERSIDADE DE SÃO PAULO. Anuários da Faculdade de Filosofia, Ciências e Letras. Vol. 1937-1938. São Paulo: Universidade de São Paulo, 1939.

FACULDADE DE FILOSOFIA, CIÊNCIAS E LETRAS DA UNIVERSIDADE DE SÃO PAULO Anuários da Faculdade de Filosofia, Ciências e Letras. v. 1934-1935. São Paulo:,Universidade de São Paulo, 1954.

FACULDADE DE FILOSOFIA, CIÊNCIAS E LETRAS DA UNIVERSIDADE DE SÃO PAULO. Dissertações e teses defendidas na FFLCH/USP: 1939-1977. Boletim Especial da FFLCH-USP, n.1, 1977.

FERRI, Mario G.; MOTOYAMA, Shozo (Orgs.). História das ciências no Brasil. São Paulo: Edusp/EPU/CNPq, 1979-1981. 3 v.

GUIA. Guia. Faculdade de Filosofia, Ciências e Letras da Universidade de São Paulo, 1943.

GUIA. Ciências Físicas e Matemáticas. Faculdade de Filosofia, Ciências e Letras da Universidade de São Paulo, 1966.

GUIA. Ciências Humanas. Faculdade de Filosofia, Ciências e Letras da Universidade de São Paulo, 1966.

GUIA. Ciências Naturais. Faculdade de Filosofia, Ciências e Letras da Universidade de São Paulo, 1966. 
GUIA. Filosofia e Educação. Faculdade de Filosofia, Ciências e Letras da Universidade de São Paulo, 1966.

GUIA. Guia. Faculdade de Filosofia, Ciências e Letras da Universidade de São Paulo, 1965. GUIA. Letras. Faculdade de Filosofia, Ciências e Letras da Universidade de São Paulo, 1966. MICELLI, Sergio. História das ciências sociais no Brasil. São Paulo: IDESP, 1989/1995. 2 v. 6o ANOS DA USP. Revista Estudos Avançados, São Paulo, n. 22. set.-dez., 1994.

SCHWARTZMANN, Simon. Formação da comunidade científica no Brasil. Rio de Janeiro: Companhia Editora Nacional, 1979. 